\title{
SHORT- AND LONG-TERM HINDLIMB IMMOBILIZATION AND RELOADING: PROFILE OF EPIGENETIC EVENTS IN GASTROCNEMIUS
}

\begin{tabular}{|r|l|}
\hline Journal: & Journal of Cellular Physiology \\
\hline Manuscript ID & JCP-16-0310.R1 \\
\hline Wiley - Manuscript type: & Original Research Article \\
\hline Date Submitted by the Author: & n/a \\
\hline Complete List of Authors: & $\begin{array}{l}\text { Chacon-Cabrera, Alba; IMIM-Hospital del Mar, UPF, PRBB, CIBERES, } \\
\text { Pulmonology-URMAR } \\
\text { Gea, Joaquim; IMIM-Hospital del Mar, Universitat Pompeu Fabra, Barcelona } \\
\text { Biomedical Research Park (PRBB), Respiratory Medicine } \\
\text { Barreiro, Esther; IMIM-Hospital del Mar, UPF, PRBB, CIBERES, } \\
\text { Pulmonology-URMAR }\end{array}$ \\
\hline Key Words: & $\begin{array}{l}\text { disuse muscle atrophy, muscle mass recovery, muscle-enriched } \\
\text { microRNAs, SIRT-1 in limb muscles, acetylated FoxO1 and FoxO3 }\end{array}$ \\
\hline \multicolumn{2}{|c|}{} \\
\hline
\end{tabular}




\title{
SHORT- AND LONG-TERM HINDLIMB IMMOBILIZATION AND RELOADING: PROFILE OF EPIGENETIC EVENTS IN GASTROCNEMIUS
}

\begin{abstract}
Alba Chacon-Cabrera ${ }^{1,2}$, Joaquim Gea ${ }^{1,2}$, Esther Barreiro ${ }^{1,2}$
${ }^{1}$ Pulmonology Department-Muscle Wasting and Cachexia in Chronic Respiratory Diseases and Lung Cancer Research group, IMIM-Hospital del Mar, Parc de Salut Mar, Health and Experimental Sciences Department (CEXS), Universitat Pompeu Fabra (UPF), Barcelona Biomedical Research Park (PRBB), C/ Dr. Aiguader, 88, Barcelona, E-08003 Spain.

${ }^{2}$ Centro de Investigación en Red de Enfermedades Respiratorias (CIBERES), Instituto de Salud Carlos III (ISCIII), Barcelona, Spain.
\end{abstract}

Corresponding author: Dr. Esther Barreiro, Pulmonology Department, IMIM-Hospital del Mar, PRBB, C/ Dr. Aiguader, 88, Barcelona, E-08003 Spain, Telephone: (+34) 933160385 , Fax: (+34) 933160410 , e-mail: ebarreiro@imim.es.

Running head: Acetylation profile in disuse muscle atrophy and recovery

Word count: 5,665

KEY WORDS:

- disuse muscle atrophy

- muscle mass recovery

- muscle-enriched microRNAs

- SIRT-1 in limb muscles

- acetylated FoxO1 and FoxO3

Number of text figures: 6

Number of tables: 1

Grant information:

Contract grant sponsor: Instituto de Salud Carlos-III, contract grant numbers, CIBERES, FIS 14/00713 (FEDER). 
Contract grant sponsor: Spanish Respiratory Society (SEPAR), contract grant numbers, SEPAR 2013 and 2016

Contract grant sponsor: Catalan Foundation of Pulmonology (FUCAP), contract grant numbers, FUCAP 2011, 2012, and 2016.

John Wiley \& Sons, Inc. 


\begin{abstract}
Skeletal muscle dysfunction and atrophy are characteristic features accompanying chronic conditions. Epigenetic events regulate muscle mass and function maintenance. We hypothesized that the pattern of epigenetic events (muscle-enriched microRNAs and histone acetylation) and acetylation of transcription factors known to signal muscle wasting may differ between early- and late-time points in skeletal muscles of mice exposed to hindlimb immobilization (I) and recovery following I. Body and muscle weights, grip strength, muscleenriched microRNAs, histone deacetylases (HDACs), acetylation of proteins, histones, and transcription factors (TF), myogenic TF factors, and muscle phenotype were assessed in gastrocnemius of mice exposed to periods (1, 2, 3, 7, 15 and 30 days, I groups) of hindlimb immobilization, and in those exposed to reloading for different periods of time $(1,3,7,15$, and 30 days, $\mathrm{R}$ groups) following 7-day immobilization. Compared to non-immobilized controls, muscle weight, limb strength, microRNAs, especially miR-486, SIRT1 levels, and slow- and fast-twitch cross-sectional areas were decreased in mice of I groups, whereas Pax7, and acetylated FoxO1 and FoxO3 levels were increased. Muscle reloading following splint removal improved muscle mass loss, strength, and fiber atrophy, by increasing microRNAs, particularly miR-486, and SIRT1 content, while decreasing acetylated FoxO1 and FoxO3 levels. In this mouse model of disuse muscle atrophy, muscle-enriched microRNAs, especially miR-486, through Pax7 regulation delayed muscle cell differentiation following unloading of gastrocnemius muscle. Acetylation of FoxO1 and 3 seemed to drive muscle mass loss and atrophy, while deacetylation of these factors through SIRT1 would enable the muscle fibers to regenerate. Word count: 248
\end{abstract}

John Wiley \& Sons, Inc. 


\section{INTRODUCTION}

Skeletal muscle dysfunction and atrophy are characteristic features that accompany chronic conditions such as respiratory and cardiac diseases, cancer, and aging (Anker et al, 1997;Barreiro et al, 2015a;Barreiro and Gea, 2015;Barreiro and Gea, 2016; Shrikrishna et al, 2012;Lexell and Downham, 1992). Moreover, atrophy of the muscle fibers also takes place when the activity of a given muscle is reduced or lost as in critical illness and/or prolonged bed rest as a result of major surgical interventions, bone fractures or during the course of severe disabling conditions (Anker et al, 1997;Barreiro et al, 2015a;Barreiro and Gea, 2015;Barreiro and Gea, 2016;Shrikrishna et al, 2012). Muscle dysfunction and wasting negatively impact the patients' quality of life through the impairment of their exercise tolerance and physical activity (Anker et al, 1997;Barreiro et al, 2015a;Barreiro and Gea, 2015;Barreiro and Gea, 2016; Barreiro, 2016; Patel et al, 2014;Shrikrishna et al, 2012;Toth et al, 2013;von Haehling and Anker, 2010). Importantly, muscle mass loss and impaired function were also shown to predict morbidity and mortality in patients with chronic heart failure (Anker et al, 1997; von Haehling and Anker, 2010) and chronic obstructive pulmonary disease (COPD) (Marquis et al, 2002;Seymour et al, 2010; Shrikrishna et al, 2012;Swallow et al, 2007) regardless of the severity of the underlying condition.

Several factors and biological mechanisms underlie the multifactorial etiology of skeletal muscle dysfunction and mass loss in patients with chronic conditions (Barreiro et al, 2010b;Barreiro et al, 2015a;Barreiro and Gea, 2015;Barreiro and Gea, 2016; Barreiro, 2016; Marin-Corral et al, 2009;Puig-Vilanova et al, 2015a;Rodriguez et al, 2012;Vogiatzis et al, 2010; Vogiatzis et al, 2011) and animal models of disuse muscle atrophy (Dalla et al, 2004;Furuno et al, 1990; Wall et al, 2016) and cachexia (Chacon-Cabrera et al, 2014;ChaconCabrera et al, 2015;Dalla et al, 2004;McClung et al, 2010;Wall et al, 2016). Inflammation, oxidative stress, metabolic derangements, structural abnormalities, and enhanced proteolysis 
have been consistently shown to be involved in the pathophysiology of muscle mass loss and dysfunction in patients and experimental models (Barreiro et al, 2010b;Barreiro et al, 2015a;Chacon-Cabrera et al, 2014;Chacon-Cabrera et al, 2015;McClung et al, 2010;Rodriguez et al, 2012; Wall et al, 2016; Beharry and Judge, 2015). Epigenetic control of cells, defined as the process whereby gene expression is regulated by heritable mechanisms that do not alter DNA sequence, significantly contributes to muscle adaptation to environmental factors such as prolonged immobilization and exercise (Barreiro and Gea, 2014;Donaldson et al, 2013;Lewis et al, 2012;Lewis et al, 2016;McCarthy and Esser, 2007;McCarthy et al, 2009). Furthermore, muscle mass maintenance and myogenesis including regeneration following injury are also tightly regulated by epigenetic mechanisms such as non-coding single-stranded RNA molecules (microRNAs) (Barreiro and Gea, 2014;Donaldson et al, 2013;Lewis et al, 2012;Lewis et al, 2016;McCarthy and Esser, 2007; McCarthy et al, 2009). Interestingly, muscle unloding and overload modified the expression of miR-1, miR-133, and miR-206, which are abundantly expressed in skeletal muscles (Allen et al, 2009;McCarthy and Esser, 2007).

Other epigenetic events such as histone acetylation, through the action of histone acetyl transferases (HATs) and deacetylases (HDACs), were also shown to be modified in the lower limb muscles of severe COPD patients with muscle wasting and weakness (Alamdari et al, 2010;Alamdari et al, 2013;Puig-Vilanova et al, 2015a). In line with this, histone acetylation and deacetylation balance is also notably involved in the regulation of muscle differentiation, development, and in the determination of muscle fiber type (McKinsey et al, 2001). Activation of transcription factors such as nuclear factor (NF)-kB and factor fork-head box (FoxO) led to muscle mass loss and atrophy in patients (Puig-Vilanova et al, 2015b) and animal models (Chacon-Cabrera et al, 2014). In skeletal muscles, other factors namely peroxisome proliferator-activated receptor gamma coactivator (PGC)-1 alpha antagonized the 
effects of FoxO1 and 3, thus delaying atrophy as a result of FoxO activity inhibition (Sandri et al, 2006). On the other hand, overexpression of sirtuin-1 (SIRT1) a HDAC was shown to attenuate muscle atrophy, while promoting muscle growth in food-deprived mice via deacetylation and inhibition of FoxO activity and activation of PGC-1 alpha (Lee and Goldberg, 2013). Furthermore, Sirt1 mRNA expression increased in skeletal muscles of three different mouse models of muscle atrophy (cast immobilization, food deprivation, and denervation) (Beharry and Judge, 2015). Whether the kinetics of SIRT1 protein expression may also vary throughout time and may influence muscle atrophy and regeneration following immobilization remains an open question.

On the basis of this, we hypothesized that the pattern of epigenetic events (microRNAs and histone acetylation) and acetylation of transcription factors known to signal muscle wasting may differ between early- and late-time points in skeletal muscles of mice exposed to hindlimb immobilization. Additionally, we also hypothesized that the same biological and epigenetic mechanisms during recovery of skeletal muscles following immobilization may also vary throughout time. Accordingly, our objectives were that in gastrocnemius of mice exposed to different periods $(1,2,3,7,15$ and 30 days) of hindlimb immobilization and in those exposed to recovery (reloading) for different time-points $(1,3,7,15$, and 30 days) after a seven-day period of immobilization, the following molecular events were explored: 1) expression levels of muscle-specific microRNAs (miR-1, miR-133, miR-206, and miR-486), 2) levels of histone and protein acetylation, histone deacetylases, and those of transcription factors involved in muscle wasting, 3) levels of myogenic transcription factors, 4) muscle type composition and morphometry, and 5) muscle function. The model of unilateral hindlimb immobilization has been previously validated in previous studies (Lang et al, 2012; Magne et al, 2011; Vargas and Lang, 2008).

John Wiley \& Sons, Inc. 


\section{MATERIALS AND METHODS}

(See additional information on all the methodologies in the online supplementary material).

\section{Animal experiments}

Female C57BL/6J mice (10 weeks old, weight $\sim 20 \mathrm{~g}$ ) were obtained from Harlan Interfauna Ibérica SL (Barcelona, Spain). Mice were kept under pathogen-free conditions in the animal house facility at Barcelona Biomedical Research Park (PRBB), with a 12:12 h light: dark cycle.

Mice were exposed to unilateral hindlimb immobilization as previously described to reproduce a model of disuse muscle atrophy (Lang et al, 2012;Magne et al, 2011;Vargas and Lang, 2008). Briefly, the left hindlimb was shaved with clippers and was enveloped using surgical tape. The hindlimb was introduced in a $1.5 \mathrm{~mL}$ microcentrifuge tube with cover and bottom lids removed, while maintaining the foot in a plantar-flexed position to induce the maximal atrophy of the target limb muscle. As the weight of the tube was approximately 0.6 $\mathrm{g}$, it did not interfere with the usual mobility of the mice. In the study, the following control groups of mice were used for different purposes. Firstly, in order to assess potential differences in body weight and food intake, age-matched non-immobilized control mice were used for all the study groups (see below). Secondly, in order to explore potential differences in the variables muscle weight, muscle phenotype and morphometry, and microRNAs expression, the contralateral non-immobilized limb was used for these experiments. Thirdly, with the aim to evaluate potential differences in several study markers using immunoblotting, a group of 30-day non-immobilized mice (period long enough to ensure potential differences if any) and a group of 7-day immobilized rodents, were used as the control group of the immobilization and recovery time-cohorts, respectively.

Three different approaches were taken in the investigation: A) non-immobilization group, B) immobilization time-cohorts (I groups), and C) recovery time-cohorts ( $\mathrm{R}$ groups), 
in which the left hindlimb of the mice was immobilized for seven consecutive days, time at which the splint was removed to let the animals move freely in their cages to evaluate muscle recovery at different time-points. Afterwards, animals were randomly assigned to the following groups (N=8/group): 1) 30-day non-immobilized control group; 2) mice immobilized for one day (1-day I); 3) mice immobilized for two days (2-day I); 4) mice immobilized for three days (3-day I); 5) mice immobilized for seven days (7-day I); 6) mice immobilized for fifteen days (15-day I); 7) mice immobilized for thirty days (30-day I); 8) mice exposed to seven days of unilateral hindlimb immobilization followed by one day recovery (1-day R); 9) mice exposed to seven days of unilateral hindlimb immobilization followed by three days recovery (3-day R); 10) mice exposed to seven days of unilateral hindlimb immobilization followed by seven days recovery (7-day R); 11) mice exposed to seven days of unilateral hindlimb immobilization followed by fifteen days recovery (15-day $\mathrm{R})$; 12) mice exposed to seven days of unilateral hindlimb immobilization followed by thirty days recovery (30-day $\mathrm{R})$.

All animal experiments were conducted in the animal facilities at Parc de Recerca Biomèdica de Barcelona (PRBB). This controlled study was designed in accordance with the ethical standards on animal experimentation (EU 2010/63 CEE, Real Decreto 53/2013 BOE 34, Spain) at PRBB and the Helsinki convention for the use and care of animals. Ethical approval was obtained by the Animal Research Committee (Animal welfare department in Catalonia, Spain, EBP-13-1485).

\section{In vivo measurements in the mice}

In all the study animals, body weight and food intake were measured at every time-point, and food and water were supplied ad libitum for the entire duration of the immobilization or recovery periods. In all mice, limb strength was determined on day 0, day 30 (nonimmobilized controls), and right at the end of each immobilization or recovery time-points (as 
describe above) using a specific grip strength meter for rodents (Bioseb, Vitrolles Cedex, France) following previously published methodologies, in which grip strength was also the end-point parameter in the different experimental models (Barreiro et al, 2010a;Barreiro et al, 2015b;Chacon-Cabrera et al, 2014;Chacon-Cabrera et al, 2015). In all mice, the four limbs equally contributed to the maneuver of grip strength. In all the animals, limb strength gain was calculated as the percentage of the measurements performed at the end of the study period with respect to the same measurements obtained at baseline (grip strength at the end of the study period-grip strength on day 0)/ grip strength on day $0 \times 100$ ).

\section{Sacrifice and sample collection}

Mice from all the experimental groups were sacrificed after the corresponding immobilization or recovery time-cohorts, or after 30 days (non-immobilized control group). Each mouse was previously inoculated intraperitoneally with $0.1 \mathrm{~mL}$ sodium pentobarbital $(60 \mathrm{mg} / \mathrm{Kg}) . \mathrm{In}$ all cases, the pedal and blink reflexes were evaluated in order to verify total anesthetic depth. Gastrocnemius muscles were obtained from all the animals at the time of sacrifice. Muscle samples were snap-frozen in liquid nitrogen to be thereafter stored frozen at $-80^{\circ} \mathrm{C}$ to be further used for the molecular analyses. Moreover, another fragment of the muscle specimens was paraffin-embedded to be used for the assessment of fiber type composition and morphometry.

\section{Biological analyses}

Muscle RNA isolation. Total RNA was first isolated from snap-frozen skeletal muscle using Trizol reagent following the manufacturer's protocol (Life tecnologies, Carlsbad, CA, USA). Total RNA concentrations were determined spectrophotometrically using the NanoDrop 1000 (Thermo Scientific, Waltham, MA, USA).

MicroRNA reverse transcription $(R T)$. MicroRNA RT was performed using TaqMan® microRNA assays (Life Technologies) as determined by quantitative real time-PCR 
amplification (qRT-PCR), specific probes (Table 1), and the manufacturer's instructions and previous studies were followed (Chacon-Cabrera et al, 2014;Chacon-Cabrera et al, 2015;PuigVilanova et al, 2014b;Puig-Vilanova et al, 2014a;Puig-Vilanova et al, 2015b).

Immunoblotting of $1 D$ electrophoresis. Protein levels of the different molecular markers analyzed in the study were explored by means of immunoblotting procedures as previously described (Chacon-Cabrera et al, 2014;Chacon-Cabrera et al, 2015;Puig-Vilanova et al, 2014b;Puig-Vilanova et al, 2014a;Puig-Vilanova et al, 2015b). Protein levels of total acetylated proteins, HDACs, myogenic transcription factors, signaling pathways, and downstream targets were identified in the gastrocnemius using specific primary antibodies: Total acetylated proteins (anti-acetyl lysine antibody, Santa Cruz Biotechnology), histone deacetylases (HDAC)3 (anti-HDAC3 antibody, Santa Cruz Biotechnology), HDAC6 (antiHDAC6 antibody, Epigentek), NAD-dependent protein deacetylase sirtuin-1 (SIRT1) (antiSIRT1 antibody, ProteinTech Group Inc.), myocyte-enhancer factor MEF2C (anti-MEF2C antibody, Santa Cruz Biotechnology), MEF2D (anti-MEF2D antibody, Santa Cruz Biotechnology), nuclear factor (NF)-кB p50 (anti-p50 antibody, Santa Cruz Biotechnology), NF-кB p65 (anti-p65 antibody, Santa Cruz Biotechnology), transcription factor fork-head box O (FoxO)-1 (anti-FoxO-1 antibody, Millipore), transcription factor fork-head box O (FoxO)-3 (anti-FoxO-3 antibody, Acris), peroxisome proliferator-activated receptor gamma coactivator 1-alpha (PGC-1 $\alpha$ ) (anti-PGC-1 $\alpha$ antibody, Santa Cruz Biotechnology), phosphatase and tensin homolog (PTEN) (anti-PTEN antibody, Santa Cruz Biotechnology), paired box protein (Pax)7 (anti-Pax7 antibody, Santa Cruz Biotechnology), acetylated histone (AcH)3 (anti-AcH3 antibody, Santa Cruz Biotechnology), and glyceraldehyde-3-phosphate dehydrogenase (GAPDH) (anti-GAPDH antibody, Santa Cruz Biotechnology). Antigens from all samples were detected with horseradish peroxidase (HRP)-conjugated secondary antibodies and a chemiluminescence kit. For each of the antigens, samples from the different groups were 
always detected in the same picture under identical exposure times. The specificity of the different antibodies was confirmed by omission of the primary antibody, and incubation of the membranes only with secondary antibodies. Acetylation levels of the transcription factors FoxO1, FoxO3, NF-kB, and PGC-1 alpha were detected as previously reported (ChaconCabrera et al, 2015). PVDF membranes were scanned with the Molecular Imager Chemidoc XRS System (Bio-Rad Laboratories, Hercules, CA, USA) using the software Quantity One version 4.6.5 (Bio-Rad Laboratories). Optical densities of specific proteins were quantified using the software Image Lab version 2.0.1 (Bio-Rad Laboratories).

Immunohistochemistry. On 3-micrometer muscle paraffin-embedded sections from gastrocnemius muscle of all study groups, myosin heavy chain (MyHC) -I and -II isoforms were identified using anti-MyHC-I (clone MHC, Biogenesis Inc.) and anti-MyHC-II antibodies (clone MY-32, Sigma-Aldrich), respectively, as published elsewhere (ChaconCabrera et al, 2014;Chacon-Cabrera et al, 2015;Puig-Vilanova et al, 2014b;Puig-Vilanova et al, 2014a;Puig-Vilanova et al, 2015b).

\section{Statistical Analysis}

Normality of the study variables were checked using the Shapiro-Wilk test. Physiological, structural, and molecular results are expressed as mean (standard deviation). The following statistical approaches were used in the study for different purposes. Firstly, total body weight and food intake of mice from each experimental group (I and R cohorts) were compared with their corresponding age-matched non-immobilized controls using the unpaired Student's Ttest. For each pair, a level of significance of $P \leq 0.05$ was established.

Secondly, deltas of the difference of mean values of the results obtained in the gastrocnemius of the immobilized hindlimb with respect to those of the contralateral nonimmobilized hindlimb, were also calculated in each animal from both cohorts (I and R), and from 30-day non-immobilized animals for another set of comparisons for the following 
variables: muscle weight, muscle phenotype and morphometry, and microRNAs expression. In this case, results are expressed as mean delta (standard deviation). Deltas obtained from each group were compared as follows: 1) deltas from mice of the immobilized cohorts (I groups) versus deltas of 30-day non-immobilized controls and 2) deltas from mice of the recovery cohorts ( $\mathrm{R}$ groups) versus deltas of mice that were exposed to seven days immobilization (7-day I, control group). Potential significant differences were assessed using one-way analysis of variance (ANOVA) with Dunnett's post hoc analysis to adjust for multiple comparisons among the study groups. A level of significance of $\mathrm{P} \leq 0.05$ was established.

Thirdly, for the following variables: Pax7, PTEN, MEF2C, MEF2D, total protein acetylation, AcH3, HDAC3, HDAC6, SIRT1, and acetylated levels of FoxO1, FoxO3, PGC$1 \alpha$, NF-kB p50, and NF-kB p65 comparisons were made between each group of mice from the different time-points of the I cohorts and the 30-day non-immobilized animals, and from the different time-points of the R cohorts compared with 7-day I. The following comparisons were performed to explore potential differences among the study groups: 1) mice from the immobilized cohorts (I groups) versus the 30-day non-immobilized controls and 2) animals from the recovery cohorts ( $\mathrm{R}$ groups) versus animals immobilized for 7 days (7-day $\mathrm{I}$, control group). In these comparisons, potential significant differences were assessed using one-way analysis of variance (ANOVA) with Dunnett's post hoc analysis to adjust for multiple comparisons among the study groups. A level of significance of $P \leq 0.05$ was established.

The sample size chosen was based on previous studies (Barreiro et al, 2015b;ChaconCabrera et al, 2014;Chacon-Cabrera et al, 2015), where very similar approaches were employed. In addition, statistical power was calculated using specific software (StudySize 2.0, CreoStat HB, Frolunda, Sweden). Limb strength gain and changes in myofiber cross sectional area were selected as the target variables to estimate the statistical power in the 
study. On the basis of a standard power statistics established at a minimum of $80 \%$ and assuming an alpha error of 0.05 , the statistical power was sufficiently high to detect a minimum difference of 25 points of delta in limb strength gain and 300 points of delta in myofiber cross sectional area respectively, among the different study groups for the given sample size and standard deviations.

\section{RESULTS}

\section{Physiological characteristics of the study animals}

Immobilization. Total body weight did not differ between animals in the I cohorts and their age-matched non-immobilized controls (Fig E1, top panel). The delta change of gastrocnemius muscle weight (immobilized versus contralateral non-immobilized hindlimb) was significantly reduced in 3-day I, 7-day I, 15-day I and 30-day I animals compared to the 30-day non-immobilized controls (Fig 1A, top panel). Limb strength gain significant decreased in all groups of I cohorts of mice compared to the non-immobilized control animals (Fig 1B, top panel).

Recovery. No significant differences were observed in total body weight (Fig E1, bottom panel) among the different groups of mice. Delta changes of gastrocnemius muscle weights were significantly greater in 15- and 30-day R groups than in control mice (7-day I animals, Fig 1A, bottom panel). Limb strength gain significantly improved in 3-, 7-, 15- and 30-day R cohorts of mice compared to control rodents (7-day I mice, Fig 1B, bottom panel).

\section{MicroRNA expression in gastrocnemius muscle}

Immobilization. Expression levels of miR-1 were significantly decreased in the gastrocnemius of 3- and 7-day I animals, and those of miR-206 were reduced in the limb muscle of 7- and 15-day I cohorts, compared to 30-day non-immobilized controls (Fig 2A, top panels). Expression levels of miR-133a did not significantly differ among the study groups in the I 
cohorts (Fig 2B, top left panel). Compared to 30-day non-immobilized rodents, the expression of miR-486 significantly decreased in the gastrocnemius of 3-, 7-, 15- and 30-day I cohorts of mice (Fig 2B, top right panel).

Recovery. Expression levels of miR-1, miR-206 and miR-486 significantly increased in all groups of the R cohorts compared to the controls (7-day I animals, Fig 2A, bottom panels, and Fig 2B, bottom right panel). Expression levels of miR-133a did not significantly differ among the study groups in the R cohorts (Fig 2B, bottom left panel).

\section{Myogenic transcription factors}

Immobilization. Protein levels of Pax7 were significantly increased in the gastrocnemius of and 3-, 7- 15-, and 30-day I cohorts compared to 30-day non-immobilized controls (Fig 3, top panel, and Fig E2). Muscle protein levels of MEF2C, MEF2D, and PTEN did not significantly differ among the study groups in the I cohorts of mice (Fig E2, and Figs E4-E6, top panels).

Recovery. Protein levels of Pax7 significantly decreased in the gastrocnemius of 3-, 7-, 15-, and 30-day R cohorts of mice compared to the 7-day immobilized controls (Fig 3, bottom panel, and Fig E3). Compared to 7-day I animals, no significant differences were observed in the levels of MEF2C, MEF2D, and PTEN in the gastrocnemius among the R cohorts of mice (Fig E3, and Figs E4-E6, bottom panels).

\section{Histone and protein acetylation levels}

Immobilization. No significant differences were observed in total protein acetylation or acetylated H3 levels in the gastrocnemius muscle among the study groups (Figs 4A and 4B, top panels, respectively, and Fig E7).

Recovery. Total protein acetylation and acetylated H3 levels did not significantly differ among the study groups in the R cohorts (Figs 4A and 4B, bottom panels, and Fig E8). 


\section{Histone deacetylase levels}

Immobilization. Levels of HDAC3 and HDAC6 did not significantly differ among the study groups in the I cohort (Figs 4C and 4D, top panels, and Fig E7). Compared to 30-day nonimmobilized controls, however, SIRT1 protein levels were significantly reduced in the gastrocnemius of 2-, 3-, 7-, 15-, and 30-day I cohorts of mice (Fig 4E, top panel, and Fig E7). Recovery. Levels of HDAC3 and HDAC6 did not significantly differ in the limb muscle among the study groups in the $\mathrm{R}$ cohort (Figs $4 \mathrm{C}$ and 4D, bottom panels, and Fig E8). Nonetheless, protein levels of SIRT1 significantly increased in the gastrocnemius of 3-, 7-, 15-, and 30-day R cohorts of mice compared to the controls (7-day I animals, Fig 4E, bottom panel, and Fig E8).

\section{Acetylation levels of transcription factors}

Immobilization. Acetylated levels of FoxO1 and FoxO3 significantly increased in the gastrocnemius of 3-, 7-, 15-, and 30-day I cohorts of mice compared to 30-day nonimmobilized animals (Figs 5A and 5B, respectively, top panels, and Fig E7). Protein levels of acetylated PGC-1 $\alpha$, NF-kB p50, and NF-kB p65 did not significantly differ among the I study cohorts of mice (Fig E7, and Figs E9-E11, top panels).

Recovery. Acetylated levels of FoxO1 and FoxO3 significantly decreased in the gastrocnemius of 3-, 7-, 15- and 30-day R groups (Figs 5A and 5B, bottom panels, and Fig E8). Protein levels of acetylated PGC-1 $\alpha$, NF-kB p50, and NF-kB p65 did not significantly differ among the study groups (Fig E8, and Figs E9-E11, bottom panels).

\section{Muscle structure characteristics}

Immobilization. Proportions of slow-twitch muscle fibers significantly decreased, while those of fast-twitch increased in 15- and 30-day I study cohorts compared to the controls (nonimmobilized mice, Fig 6A, top panel). The sizes of both slow- and fast-twitch fibers were 
significantly reduced in the gastrocnemius of 7-, 15-, and 30-day I mice compared to the controls (non-immobilized animals, Fig 6B, top panel).

Recovery. The proportions of slow- and fast-twith fibres did not signficantly differ among the $\mathrm{R}$ cohorts of mice (Fig 6A, bottom panel). The size of both fast- and slow-twitch fibers significantly increased in the gastrocnemius of 7-, 15-, and 30-day R study cohorts compared to the controls (7-day immobilized animals, Fig 6B, bottom panel).

\section{DISCUSSION}

Epigenetic mechanisms regulate muscle development in embryonic myogenesis and during regeneration following muscle injury. As such, epigenetics regulates maintenance of satellite cells in the quiescence state and may also trigger the proliferation and differentiation processes of these cells through different mechanisms. Moreover, in adaptation to environmental factors such as reduced activity and reloading of the muscles with normal activity, which is tightly regulated by several biological events, epigenetics may also play a relevant role in in vivo models. The non-coding single-stranded microRNAs posttranscriptionally regulate gene expression in cells. Despite that most of the microRNAs identified so far regulate different processes in several cell types, certain microRNAs are tissue specific. For instance, miR-1, miR-133, and miR-206 are abundantly expressed within skeletal muscles and are identified as muscle specific microRNAs (myomiRs). Specifically, miR-1 and miR-133 are expressed in both skeletal and cardiac muscles, while miR-206 can only be found in the former tissue (Dey et al, 2011; Weintraub et al, 1989).

In the current investigation, expression levels of miR-1 were significantly reduced in the muscles of the 3- and 7-day I cohorts of mice, while they returned to control levels in the 30-day I. Additionally, expression of miR-206 significantly decreased in the gastrocnemius of 7- and 15-day I groups. Interestingly, expression of both miR-1 and miR-206 returned to 
baseline control levels in the muscles of all groups of the recovery cohort of mice, being significantly greater than to those detected in the 7-day I rodents. Nonetheless, expression levels of miR-133 did not significantly differ across groups in the immobilization or the recovery study cohorts. These microRNAs exert different functions within the skeletal muscle fibers. For instance, miR-1 and miR-206 promote muscle cell differentiation and innervation through several downstream mechanisms, while miR-133 stimulates myoblast proliferation by repressing the serum response factor (SRF), which prevents myotube formation (Chen et al, 2006; Kim et al, 2006). The findings encountered in the present study imply that muscle differentiation may be transiently hampered in the gastrocnemius following 3-, 7-, and 15-day immobilization as a result of the downregulation of miR-1 and miR-206 expression, respectively. Interestingly, prolonged immobilization (30-day cohort) did not modify expression levels of these muscle-specific microRNAs probably as a result of the contribution of other mechanisms as discussed below.

The paired-homeobox transcription factors Pax3 and Pax7 genes are involved in early striation during myogenesis. Pax3 is required for the formation of a template of initial fibers to which Pax7-positive fibers are incorporated to establish a satellite cell pool. In the current study, levels of Pax7 increased in the 3-day I cohort of mice and thereafter up to the 30-day I group of rodents. Interestingly, expression of Pax7 decreased in all the recovery groups of animals except for the 1-day R cohort. These findings may imply that proliferarion of muscle satellite cells may take place during unloading of the gastrocnemius as was shown previously in gastrocnemius of mice exposed to hindlimb suspension (Ferreira et al, 2006), while hindlimb reloading downregulated Pax7 expression to allow muscle differentiation to occur as a natural phase in the process of myogenesis (Dey et al, 2011). Nonetheless, future studies will have to confirm this hypothesis in the current experimental model of disuse muscle atrophy. 
Other non-muscle specific microRNAs, which are also abundantly expressed in muscles, may regulate skeletal muscle development and phenotype. As such, miR-486 induces myoblast differentiation through downregulating Pax7 (Dey et al, 2011). Thus, downregulation of miR-486 results in maintenance of Pax7 activity, which delays the muscle differentiation process. In the current investigation, the expression of miR-486 was downregulated in the muscles of the immobilized mice from the 3-day I and thereafter including the 30-day I group of rodents. On the basis of these findings, muscle differentiation rather than proliferation was most likely to be impaired in the mice exposed to hindlimb immobilization in this model. Interestingly, miR-486 muscle expression significantly increased following one-day recovery and thereafter in all the study cohorts, and Pax7 expression was reduced in the 3-day R cohort probably via a Pax7-induced mechanism. Other transcription factors such as PTEN and MEF2 may also act downstream of miR-486 activity. Nonetheless, no significant differences in the expression of PTEN, MEF2C, or MEF2D were observed in the limb muscle among the study groups of mice in the two experimental cohorts, implying that in this model, those transcription factors do not play a role in myogenesis following muscle unloading. Taken together, these results suggest that miR-486 may regulate differentiation in this model of disuse muscle atrophy probably through the regulation of Pax7 expression. Nevertheless, future studies aimed specifically to explore this pathway will have to be designed in order to confirm such a hypothesis.

Transcription states are regulated by post-translational modifications of histones that are epigenetic markers for chromatin structure and function. Gene expression may be regulated as a result of lysine residue acetylation, which triggers chromatin remodeling. In principle histone acetylation induces gene transcription, while histone deacetylation silences gene expression (Suka et al, 2001; Vempati et al, 2010). In the study, no significant differences were seen in lysine-acetylated histone-3 levels in the gastrocnemius among study groups 
following unloading or reloading experiments. Additionally, levels of total muscle protein acetylation were not altered by hindlimb unloading in either short- or long-time cohorts of mice. Reloading of the mouse hindlimb did not induce any modifications in the levels of muscle lysine-acetylated histone-3 or total protein acetylation levels. In keeping with these results, protein levels of HDAC3 or HDAC6 did not significantly differ among the study groups in either the immobilization or recovery study cohorts. These findings are counter to results shown in models of muscle wasting accompanying chronic conditions such as patients with COPD (Puig-Vilanova et al, 2015a) and cancer-induced cachexia in mice (Alamdari et al, 2010;Chacon-Cabrera et al, 2015;Sadoul et al, 2008), in which levels of HDACs were reduced leading to a rise in histone and total protein acetylation levels.

Importantly, in other models of muscle atrophy, mRNA levels of Hdac3, Hdac4, and Hdac 6 were shown to be upregulated in skeletal muscles of mice exposed to cast immobilization, food deprivation, and denervation after several days (Beharry and Judge, 2015). Moreover, in another investigation of the same group (Beharry et al, 2014), the blockade of HADC1, which activated FoxO, was sufficient to induce a program of muscle atrophy in mice exposed to cast immobilization for several days and to induce a program of protein ubiquitination (Ryder et al, 2015). Additionally, in another mouse model of denervation, FoxO3 activity was also shown to be negatively regulated by acetylation and ubiquitination in a time-dependent fashion (Bertaggia et al, 2012). Collectively, these results imply that histone acetylation seemed to drive muscle atrophy in several models of disuse muscle atrophy and in muscle wasting associated with serious illnesses in both human and animal models (Alamdari et al, 2010;Chacon-Cabrera et al, 2015;Sadoul et al, 2008;PuigVilanova et al, 2015a), despite that no alterations in histone acetylation levels were found in the current model. Differences in the intensity and duration of the models and fiber type composition of the target muscles may account for discrepancies in histone acetylation levels 
among the models as has been recently demonstrated to occur in different muscles of rats and models of atrophy (Kawano et al, 2015).

Protein levels of SIRT-1 were reduced in the gastrocnemius of 2-day I group of mice and thereafter including those exposed to hindlimb immobilization for 30 days. Compared to the 7-day I animals, SIRT-1 levels significantly increased in the limb muscle of the recovery groups of mice except for those of 1-day R group. SIRT-1 protein deacetylase exerts a wide range of beneficial effects in tissues through the action of several mediators such as activation of PGC-1alpha (Gerhart-Hines et al, 2007;Lagouge et al, 2006;Lee and Goldberg, 2013) and inhibition of FoxO1 and FoxO3 activities (Lee and Goldberg, 2013). The latter effects block the activation of atrogenes and autophagy genes, thus preventing muscles from undergoing further proteolysis and mass loss.

Interestingly, SIRT-1 also deacetylases lysine residues of nuclear proteins other than histones such as NF-kB subunits, thus regulating the transcription of target proteins, since DNA binding activity of those transcription factors was shown to be reduced (Kiernan et al, 2003). In the current study, a significant rise in levels of acetylated FoxO1 and 3 were detected in the limb muscle of 3-day I and thereafter up to the 30-day I group of mice. Conversely, levels of acetylated FoxO1 and 3 significantly decreased in the muscles of the recovery cohort except for animals in the 1-day $\mathrm{R}$ group (Lee and Goldberg, 2013). These results are in agreement with those previously shown in fast-twitch muscles (tibialis anterior) of mice in a model of food deprivation-induced muscle atrophy, in which SIRT-1 levels were also significantly reduced, leading to activation of FoxO1 and 3 in the mouse muscles (Lee and Goldberg, 2013). Importantly, differences in the levels of acetylated NF-kB subunits, p50 and p65 did not signficantly differ in the limb muscle among study groups following unloading or reloading experimental conditions. These findings were somehow expected as activation of NF-kB pathway has been shown to rather drive muscle atrophy and mass loss in 
models of denervation and food deprivation (Lee and Goldberg, 2015). On the other hand, phosphorylation rather than acetylation of NF-kB pathway may be the predominant posttranslational modification leading to its activation, as previously shown in models of cancer-induced cachexia (Chacon-Cabrera, 2014; Puig-Vilanova, 2015b). Collectively, these findings suggest that acetylation of FoxO1 and 3 as a result of SIRT-1 downregulation rather than that of PGC-1alpha or NF-kB is a potential mechanism that underlies muscle mass loss in this model of hindlimb unloading. Importantly, reloading of the gastrocnemius induced a rise in the levels of SIRT-1 together with a significant decline in acetylation levels of FoxO1 and 3 in the 3-day R group of mice and thereafter up to the 30-day R animals.

A significant reduction in the sizes of both slow- and fast twitch muscle fibers was detected after seven days of immobilization compared to control mice. Importantly, in both muscle fiber types, cross-sectional areas were similar to control muscles following 15 days of reloading. These outcomes are similar to those reported in former studies in which other models of disuse muscle atrophy were examined (Adams et al, 2003;Callahan et al, 2015). Whole muscle weight also recovered in animals of the 15-day R compared to the controls (7day I). It seems that muscle mass probably relies on the size of its muscle fibers in this experimental model.

A switch to a less fatigue-resistant phenotype has been consistently shown in skeletal muscles of the lower limbs in patients with chronic conditions such as COPD (Barreiro et al, 2015a;Fermoselle et al, 2012;Puig-Vilanova et al, 2015b;Puig-Vilanova et al, 2015a), cancer cachexia (Puig-Vilanova et al, 2015b), and chronic heart failure (Anker et al, 1997;Anker and Sharma, 2002). In the current study, the proportions of slow-twitch muscle fibers significantly decreased in the gastrocnemius of the 15-day I cohort, while a significant rise in those of fast-twitch fibers was detected in the same muscles. Reduced physical activity and deconditioning are probably the most relevant factors that drive muscle fiber atrophy and the 
characteristic slow-to-fast fiber type switch observed in skeletal muscles of patients with chronic conditions, which seriously impair their exercise capacity and tolerance (Barreiro et al, 2015a;Barreiro and Gea, 2016;Maltais et al, 2014;Puig-Vilanova et al, 2015a). It should also be mentioned that the switch to a less fatigue-resistant phenotype was not restored during the recovery period even after 30 days of hindlimb reloading. These results imply that a longer reloading period than 30 days is probably required for the muscle to fully regenerate ands recover its normal proportions of slow- and fast-twitch fibers.

Importantly, the decrease in gastrocnemius weight and limb strength were significantly evident in animals exposed to early time-points (one- and three-day cohorts) of hindlimb immobilization, suggesting that the electrophysiological properties of the hindlimb muscles (strength) are particularly sensitive to experience alterations even at early stages of muscle unloading.

\section{Conclusions}

In this mouse model of disuse muscle atrophy, muscle-enriched microRNAs, especially miR486, through Pax7 regulation delayed muscle cell differentiation as part of the muscle development process following unloading of the gastrocnemius. Furthermore, acetylation of FoxO1 and 3 seemed to drive muscle mass loss and atrophy, while deacetylation of these factors through SIRT1 would enable the muscle fibers to regenerate. These fundings offer therapeutic strategies to combat muscle atrophy by enhancing SIRT1 activity in models of disuse. 


\section{ACKNOWLEDGEMENTS}

The authors are grateful to Ms. Isabel Fabra-Heredia, Mireia Solà-Colom, Eugènia Serramontmany, and Estefania Carrillo for their help with part of the laboratory experiments.

Authors' conflicts of interest in relation to the study: None to declare.

Editorial support: None to declare.

John Wiley \& Sons, Inc. 


\section{Literature Cited}

Adams GR, Caiozzo VJ, Baldwin KM (2003). Skeletal muscle unweighting: spaceflight and ground-based models. J Appl Physiol (1985 ) 95:2185-2201.

Alamdari N, Aversa Z, Castillero E, Hasselgren PO (2013). Acetylation and deacetylation-novel factors in muscle wasting. Metabolism 62:1-11.

Alamdari N, Smith IJ, Aversa Z, Hasselgren PO (2010). Sepsis and glucocorticoids upregulate p300 and downregulate HDAC6 expression and activity in skeletal muscle. Am J Physiol Regul Integr Comp Physiol 299:R509-R520.

Allen DL, Bandstra ER, Harrison BC, Thorng S, Stodieck LS, Kostenuik PJ, Morony S, Lacey DL, Hammond TG, Leinwand LL, Argraves WS, Bateman TA, Barth JL (2009). Effects of spaceflight on murine skeletal muscle gene expression. J Appl Physiol 106:582595.

Anker SD, Ponikowski P, Varney S, Chua TP, Clark AL, Webb-Peploe KM, Harrington D, Kox WJ, Poole-Wilson PA, Coats AJ (1997). Wasting as independent risk factor for mortality in chronic heart failure. Lancet 349:1050-1053.

Anker SD, Sharma R (2002). The syndrome of cardiac cachexia. Int J Cardiol 85:51-66.

Barreiro E, Bustamante V, Cejudo P, Galdiz JB, Gea J, de LP, Martinez-Llorens J, Ortega F, Puente-Maestu L, Roca J, Rodriguez-Gonzalez Moro JM (2015a). Guidelines for the evaluation and treatment of muscle dysfunction in patients with chronic obstructive pulmonary disease. Arch Bronconeumol 51:384-395.

Barreiro E, Gea J (2014). Epigenetics and muscle dysfunction in chronic obstructive pulmonary disease. Transl Res 165:61-73.

Barreiro E, Gea J (2015). Respiratory and Limb Muscle Dysfunction in COPD. COPD $12: 413-426$.

Barreiro E, Gea J (2016). Molecular and biological pathways of skeletal muscle dysfunction in chronic obstructive pulmonary disease. Chron Respir Dis 13:297-311.

Barreiro E (2016). Skeletal muscle dysfunction in COPD: novelties in the last decade. Arch Bronconeumol DOI:10.1016/j.arbres.2016.07.009

Barreiro E, Marin-Corral J, Sanchez F, Mielgo V, Alvarez FJ, Galdiz JB, Gea J (2010a). Reference values of respiratory and peripheral muscle function in rats. J Anim Physiol Anim Nutr (Berl) 94:e393-e401.

Barreiro E, Peinado VI, Galdiz JB, Ferrer E, Marin-Corral J, Sanchez F, Gea J, Barbera JA (2010b). Cigarette smoke-induced oxidative stress: A role in chronic obstructive pulmonary disease skeletal muscle dysfunction. Am J Respir Crit Care Med 182:477-488.

Barreiro E, Puig-Vilanova E, Marin-Corral J, Chacon-Cabrera A, Salazar-Degracia A, Mateu X, Puente-Maestu L, Garcia-Arumi E, Andreu AL, Molina L (2015b). Therapeutic Approaches in Mitochondrial Dysfunction, Proteolysis, and Structural Alterations of Diaphragm and Gastrocnemius in Rats With Chronic Heart Failure. J Cell Physiol. 
Beharry AW, Judge AR (2015). Differential expression of HDAC and HAT genes in atrophying skeletal muscle. Muscle Nerve 52:1098-1101.

Beharry AW, Sandesara PB, Roberts BM, Ferreira LF, Senf SM, Judge AR (2014). HDAC1 activates FoxO and is both sufficient and required for skeletal muscle atrophy. J Cell Sci 127:1441-1453.

Bertaggia E, Coletto L, Sandri M (2012). Posttranslational modifications control FoxO3 activity during denervation. Am J Physiol Cell Physiol 302:C587-C596.

Callahan DM, Tourville TW, Miller MS, Hackett SB, Sharma H, Cruickshank NC, Slauterbeck JR, Savage PD, Ades PA, Maughan DW, Beynnon BD, Toth MJ (2015). Chronic disuse and skeletal muscle structure in older adults: sex-specific differences and relationships to contractile function. Am J Physiol Cell Physiol 308:C932-C943.

Chacon-Cabrera A, Fermoselle C, Salmela I, Yelamos J, Barreiro E (2015). MicroRNA expression and protein acetylation pattern in respiratory and limb muscles of Parp-1(-/-) and Parp-2(-/-) mice with lung cancer cachexia. Biochim Biophys Acta 1850:2530-2543.

Chacon-Cabrera A, Fermoselle C, Urtreger AJ, Mateu-Jimenez M, Diament MJ, De Kier Joffe ED, Sandri M, Barreiro E (2014). Pharmacological strategies in lung cancer-induced cachexia: effects on muscle proteolysis, autophagy, structure, and weakness. J Cell Physiol 229:1660-1672.

Chen JF, Mandel EM, Thomson JM, Wu Q, Callis TE, Hammond SM, Conlon FL, Wang DZ (2006). The role of microRNA-1 and microRNA-133 in skeletal muscle proliferation and differentiation. Nat Genet 38:228-233.

Dalla LL, Ravara B, Volterrani M, Gobbo V, Della BM, Angelini A, Danieli BD, Germinario E, Vescovo G (2004). Beneficial effects of GH/IGF-1 on skeletal muscle atrophy and function in experimental heart failure. Am J Physiol Cell Physiol 286:C138-C144.

Dey BK, Gagan J, Dutta A (2011). miR-206 and -486 induce myoblast differentiation by downregulating Pax7. Mol Cell Biol 31:203-214.

Donaldson A, Natanek SA, Lewis A, Man WD, Hopkinson NS, Polkey MI, Kemp PR (2013). Increased skeletal muscle-specific microRNA in the blood of patients with COPD. Thorax 68:1140-1149.

Fermoselle C, Rabinovich R, Ausin P, Puig-Vilanova E, Coronell C, Sanchez F, Roca J, Gea J, Barreiro E (2012). Does oxidative stress modulate limb muscle atrophy in severe COPD patients? Eur Respir J 40:851-862.

Ferreira R, Neuparth MJ, Ascensao A, Magalhaes J, Vitorino R, Duarte JA, Amado F (2006). Skeletal muscle atrophy increases cell proliferation in mice gastrocnemius during the first week of hindlimb suspension. Eur J Appl Physiol 97:340-346.

Furuno K, Goodman MN, Goldberg AL (1990). Role of different proteolytic systems in the degradation of muscle proteins during denervation atrophy. J Biol Chem 265:8550-8557. 
Gerhart-Hines Z, Rodgers JT, Bare O, Lerin C, Kim SH, Mostoslavsky R, Alt FW, Wu Z, Puigserver P (2007). Metabolic control of muscle mitochondrial function and fatty acid oxidation through SIRT1/PGC-1alpha. EMBO J 26:1913-1923.

Kawano F, Nimura $\quad$ K, Ishino $\quad$ S, Nakai $\quad$ N, Nakata $\quad$ K, Ohira $\quad$ Y. Differences in histone modifications between slow- and fast-twitch muscle of adult rats and following overload, denervation, or valproic acid administration (2015). J Appl Physiol 119:1042-52.

Kiernan R, Bres V, Ng RW, Coudart MP, El MS, Sardet C, Jin DY, Emiliani S, Benkirane M (2003). Post-activation turn-off of NF-kappa B-dependent transcription is regulated by acetylation of p65. J Biol Chem 278:2758-2766.

Kim HK, Lee YS, Sivaprasad U, Malhotra A, Dutta A (2006). Muscle-specific microRNA miR-206 promotes muscle differentiation. J Cell Biol 174:677-687.

Lagouge M, Argmann C, Gerhart-Hines Z, Meziane H, Lerin C, Daussin F, Messadeq N, Milne J, Lambert P, Elliott P, Geny B, Laakso M, Puigserver P, Auwerx J (2006). Resveratrol improves mitochondrial function and protects against metabolic disease by activating SIRT1 and PGC-1alpha. Cell 127:1109-1122.

Lang SM, Kazi AA, Hong-Brown L, Lang CH (2012). Delayed recovery of skeletal muscle mass following hindlimb immobilization in mTOR heterozygous mice. PLoS One 7:e38910.

Lee D, Goldberg AL (2013). SIRT1 protein, by blocking the activities of transcription factors FoxO1 and FoxO3, inhibits muscle atrophy and promotes muscle growth. J Biol Chem 288:30515-30526.

Lee D, Goldberg AL (2015). Muscle Wasting in Fasting Requires Activation of NF- $\kappa$ B and Inhibition of AKT/Mechanistic Target of Rapamycin (mTOR) by the Protein Acetylase, GCN5. J Biol Chem 290:30269-30270.

Lewis A, Lee JY, Donaldson AV, Natanek SA, Vaidyanathan S, Man WD, Hopkinson NS, Sayer AA, Patel HP, Cooper C, Syddall H, Polkey MI, Kemp PR (2016). Increased expression of H19/miR-675 is associated with a low fat-free mass index in patients with COPD. J Cachexia Sarcopenia Muscle.

Lewis A, Riddoch-Contreras J, Natanek SA, Donaldson A, Man WD, Moxham J, Hopkinson NS, Polkey MI, Kemp PR (2012). Downregulation of the serum response factor/miR-1 axis in the quadriceps of patients with COPD. Thorax 67:26-34.

Lexell J, Downham D (1992). What is the effect of ageing on type 2 muscle fibres? J Neurol Sci 107:250-251.

Magne H, Savary-Auzeloux I, Vazeille E, Claustre A, Attaix D, Anne L, Veronique SL, Philippe G, Dardevet D, Combaret L (2011). Lack of muscle recovery after immobilization in old rats does not result from a defect in normalization of the ubiquitin-proteasome and the caspase-dependent apoptotic pathways. J Physiol 589:511-524.

Maltais F, Decramer M, Casaburi R, Barreiro E, Burelle Y, Debigare R, Dekhuijzen PN, Franssen F, Gayan-Ramirez G, Gea J, Gosker HR, Gosselink R, Hayot M, Hussain SN, Janssens W, Polkey MI, Roca J, Saey D, Schols AM, Spruit MA, Steiner M, Taivassalo T, Troosters T, Vogiatzis I, Wagner PD (2014). An official American Thoracic 
Society/European Respiratory Society statement: update on limb muscle dysfunction in chronic obstructive pulmonary disease. Am J Respir Crit Care Med 189:e15-e62.

Marin-Corral J, Minguella J, Ramirez-Sarmiento AL, Hussain SN, Gea J, Barreiro E (2009). Oxidised proteins and superoxide anion production in the diaphragm of severe COPD patients. Eur Respir J 33:1309-1319.

Marquis K, Debigare R, Lacasse Y, LeBlanc P, Jobin J, Carrier G, Maltais F (2002). Midthigh muscle cross-sectional area is a better predictor of mortality than body mass index in patients with chronic obstructive pulmonary disease. Am J Respir Crit Care Med 166:809-813.

McCarthy JJ, Esser KA (2007). MicroRNA-1 and microRNA-133a expression are decreased during skeletal muscle hypertrophy. J Appl Physiol 102:306-313.

McCarthy JJ, Esser KA, Peterson CA, Dupont-Versteegden EE (2009). Evidence of MyomiR network regulation of beta-myosin heavy chain gene expression during skeletal muscle atrophy. Physiol Genomics 39:219-226.

McClung JM, Judge AR, Powers SK, Yan Z (2010). p38 MAPK links oxidative stress to autophagy-related gene expression in cachectic muscle wasting. Am J Physiol Cell Physiol 298:C542-C549.

McKinsey TA, Zhang CL, Olson EN (2001). Control of muscle development by dueling HATs and HDACs. Curr Opin Genet Dev 11:497-504.

Patel MS, Natanek SA, Stratakos G, Pascual S, Martinez-Llorens J, Disano L, Terzis G, Hopkinson NS, Gea J, Vogiatzis I, Maltais F, Polkey MI (2014). Vastus lateralis fiber shift is an independent predictor of mortality in chronic obstructive pulmonary disease. Am J Respir Crit Care Med 190:350-352.

Puig-Vilanova E, Aguilo R, Rodriguez-Fuster A, Martinez-Llorens J, Gea J, Barreiro E (2014a). Epigenetic mechanisms in respiratory muscle dysfunction of patients with chronic obstructive pulmonary disease. PLoS One 9:e111514.

Puig-Vilanova E, Ausin P, Martinez-Llorens J, Gea J, Barreiro E (2014b). Do epigenetic events take place in the vastus lateralis of patients with mild chronic obstructive pulmonary disease? PLoS One 9:e102296.

Puig-Vilanova E, Martinez-Llorens J, Ausin P, Roca J, Gea J, Barreiro E (2015a). Quadriceps muscle weakness and atrophy are associated with a differential epigenetic profile in advanced COPD. Clin Sci (Lond) 128:905-921.

Puig-Vilanova E, Rodriguez DA, Lloreta J, Ausin P, Pascual-Guardia S, Broquetas J, Roca J, Gea J, Barreiro E (2015b). Oxidative stress, redox signaling pathways, and autophagy in cachectic muscles of male patients with advanced COPD and lung cancer. Free Radic Biol Med 79:91-108.

Ryder DJ, Judge SM, Beharry AW, Farnsworth CL, Silva JC, Judge AR (2015). Identification of the Acetylation and Ubiquitin-Modified Proteome during the Progression of Skeletal Muscle Atrophy. PLoS One 10:e0136247. 
Rodriguez DA, Kalko S, Puig-Vilanova E, Perez-Olabarria M, Falciani F, Gea J, Cascante M, Barreiro E, Roca J (2012). Muscle and blood redox status after exercise training in severe COPD patients. Free Radic Biol Med 52:88-94.

Sadoul K, Boyault C, Pabion M, Khochbin S (2008). Regulation of protein turnover by acetyltransferases and deacetylases. Biochimie 90:306-312.

Sandri M, Lin J, Handschin C, Yang W, Arany ZP, Lecker SH, Goldberg AL, Spiegelman BM (2006). PGC-1alpha protects skeletal muscle from atrophy by suppressing FoxO3 action and atrophy-specific gene transcription. Proc Natl Acad Sci U S A 103:16260-16265.

Seymour JM, Spruit MA, Hopkinson NS, Natanek SA, Man WD, Jackson A, Gosker HR, Schols AM, Moxham J, Polkey MI, Wouters EF (2010). The prevalence of quadriceps weakness in COPD and the relationship with disease severity. Eur Respir J 36:81-88.

Shrikrishna D, Patel M, Tanner RJ, Seymour JM, Connolly BA, Puthucheary ZA, Walsh SL, Bloch SA, Sidhu PS, Hart N, Kemp PR, Moxham J, Polkey MI, Hopkinson NS (2012). Quadriceps wasting and physical inactivity in patients with COPD. Eur Respir J 40:11151122 .

Suka N, Suka Y, Carmen AA, Wu J, Grunstein M (2001). Highly specific antibodies determine histone acetylation site usage in yeast heterochromatin and euchromatin. Mol Cell $8: 473-479$.

Swallow EB, Reyes D, Hopkinson NS, Man WD, Porcher R, Cetti EJ, Moore AJ, Moxham J, Polkey MI (2007). Quadriceps strength predicts mortality in patients with moderate to severe chronic obstructive pulmonary disease. Thorax 62:115-120.

Toth MJ, Miller MS, Callahan DM, Sweeny AP, Nunez I, Grunberg SM, Der-Torossian H, Couch ME, Dittus K (2013). Molecular mechanisms underlying skeletal muscle weakness in human cancer: reduced myosin-actin cross-bridge formation and kinetics. J Appl Physiol 114:858-868.

Vargas R, Lang CH (2008). Alcohol accelerates loss of muscle and impairs recovery of muscle mass resulting from disuse atrophy. Alcohol Clin Exp Res 32:128-137.

Vempati RK, Jayani RS, Notani D, Sengupta A, Galande S, Haldar D (2010). p300-mediated acetylation of histone $\mathrm{H} 3$ lysine 56 functions in DNA damage response in mammals. J Biol Chem 285:28553-28564.

Vogiatzis I, Simoes DC, Stratakos G, Kourepini E, Terzis G, Manta P, Athanasopoulos D, Roussos C, Wagner PD, Zakynthinos S (2010). Effect of pulmonary rehabilitation on muscle remodelling in cachectic patients with COPD. Eur Respir J 36:301-310.

Vogiatzis I, Terzis G, Stratakos G, Cherouveim E, Athanasopoulos D, Spetsioti S, Nasis I, Manta P, Roussos C, Zakynthinos S (2011). Effect of pulmonary rehabilitation on peripheral muscle fiber remodeling in patients with COPD in GOLD stages II to IV. Chest 140:744-752.

von Haehling S, Anker SD (2010). Cachexia as a major underestimated and unmet medical need: facts and numbers. J Cachexia Sarcopenia Muscle 1:1-5. 
Wall BT, Dirks ML, Snijders T, van Dijk JW, Fritsch M, Verdijk LB, van Loon LJ (2016). Short-term muscle disuse lowers myofibrillar protein synthesis rates and induces anabolic resistance to protein ingestion. Am J Physiol Endocrinol Metab 310:E137-E147.

Weintraub H, Tapscott SJ, Davis RL, Thayer MJ, Adam MA, Lassar AB, Miller AD (1989). Activation of muscle-specific genes in pigment, nerve, fat, liver, and fibroblast cell lines by forced expression of MyoD. Proc Natl Acad Sci U S A 86:5434-5438.

John Wiley \& Sons, Inc. 


\section{FIGURE LEGENDS:}

Figure 1: (A) Mean values and standard deviation of delta of the variable gastrocnemius weight in the immobilization (top panel) and recovery (bottom panel) cohorts of mice. Definition of abbreviations: g, grams; I, immobilization; R, recovery. Statistical significance is represented as follows: *, $\mathrm{p} \leq 0.05, * *, \mathrm{p} \leq 0.01, * * *, \mathrm{p} \leq 0.001$, and n.s., non-significant differences between any of the immobilized animals and the non-immobilized controls; $\S$, $\mathrm{p} \leq 0.01$, and n.s., non-significant differences between any of the $\mathrm{R}$ groups of animals and the 7-day I mice. (B) Mean values and standard deviation of limb strength gain of the immobilization (top panel) and recovery (bottom panel) cohorts of mice. Definition of abbreviations: I, immobilization; $\mathrm{R}$, recovery. Statistical significance is represented as follows: $* *, \mathrm{p} \leq 0.01$, and $* * *, \mathrm{p} \leq 0.001$ between any of the immobilized animals and the nonimmobilized controls; $\S, \mathrm{p} \leq 0.05, \quad \S \S, \mathrm{p} \leq 0.01, \quad \S \S \S, \mathrm{p} \leq 0.001$, and n.s., non-significant differences between any of the R groups of animals and the 7-day I mice.

Figure 2: (A) Mean values and standard deviation of delta of miR-1 (top and bottom left panels) and miR-206 (top and bottom right panels) of the immobilization (top panels) and recovery (bottom panels) cohorts of mice. Definition of abbreviations: a.u., arbitrary units; I, immobilization; R, recovery. Statistical significance is represented as follows: *, $\mathrm{p} \leq 0.05, * *$, $\mathrm{p} \leq 0.01, * * *, \mathrm{p} \leq 0.001$, and n.s., non-significant differences between any of the immobilized animals and the non-immobilized controls; $\S \S, \mathrm{p} \leq 0.01$, and $\S \S \S, \mathrm{p} \leq 0.001$ between any of the R groups of animals and the 7-day I mice. (B) Mean values and standard deviation of delta of miR-133a (top and bottom left panels) and miR-486 (top and bottom right panels) of the immobilization (top panels) and recovery (bottom panels) cohorts of mice. Definition of abbreviations: a.u., arbitrary units; I, immobilization; R, recovery. Statistical significance is represented as follows: $* *, \mathrm{p} \leq 0.01, * * *, \mathrm{p} \leq 0.001$, and n.s., non-significant differences between any of the immobilized animals and the non-immobilized controls; $\S, \mathrm{p} \leq 0.05, \S \S$, 
$\mathrm{p} \leq 0.001$, and n.s., non-significant differences between any of the $\mathrm{R}$ groups of animals and the 7-day I mice.

Figure 3: Mean values and standard deviation of $\operatorname{Pax} 7$ protein content in the gastrocnemius of the immobilization (top panel) and recovery (bottom panel) cohorts of mice, as measured by optical densities in arbitrary units (OD, a.u.). Note that as arbitrary units were used for the measurement of the optical densities in each set of immunoblots (see methods), scale bars in the ordinate axis are different in the graphs corresponding to the immobilization groups from those in the recovery cohorts. Definition of abbreviations: Pax, Paired box protein; OD, optical densities; a.u., arbitrary units; I, immobilization; R, recovery. Statistical significance is represented as follows: $*, p \leq 0.05$, and n.s., non-significant differences between any of the immobilized animals and the non-immobilized controls; $\S, \mathrm{p} \leq 0.05, \S \S, \mathrm{p} \leq 0.01, \S \S \S, \mathrm{p} \leq 0.001$, and n.s., non-significant differences between any of the R groups of animals and the 7-day I mice.

Figure 4: (A) Mean values and standard deviation of total protein acetylation content in the gastrocnemius of the immobilization (top panel) and recovery (bottom panel) cohorts of mice, as measured by optical densities in arbitrary units (OD, a.u.). Note that as arbitrary units were used for the measurement of the optical densities in each set of immunoblots (see methods), scale bars in the ordinate axis are different in the graphs corresponding to the immobilization groups from those in the recovery cohorts. Definition of abbreviations: OD, optical densities; a.u., arbitrary units; I, immobilization; R, recovery. Statistical significance is represented as follows: n.s., non-significant differences between any of the immobilized animals and the non-immobilized controls; n.s., non-significant differences between any of the $\mathrm{R}$ groups of animals and the 7-day I mice. (B) Mean values and standard deviation of acetylated histone 3 protein content in the gastrocnemius of the immobilization (top panel) and recovery (bottom panel) cohorts of mice, as measured by optical densities in arbitrary units (OD, a.u.). Note that 
as arbitrary units were used for the measurement of the optical densities in each set of immunoblots (see methods), scale bars in the ordinate axis are different in the graphs corresponding to the immobilization groups from those in the recovery cohorts. Definition of abbreviations: Ac, acetylated; H3, histone 3; OD, optical densities; a.u., arbitrary units; I, immobilization; R, recovery. Statistical significance is represented as follows: n.s., nonsignificant differences between any of the immobilized animals and the non-immobilized controls; n.s., non-significant differences between any of the R groups of animals and the 7day I mice. (C) Mean values and standard deviation of HDAC3 protein content in the gastrocnemius of the immobilization (top panel) and recovery (bottom panel) cohorts of mice, as measured by optical densities in arbitrary units (OD, a.u.). Note that as arbitrary units were used for the measurement of the optical densities in each set of immunoblots (see methods), scale bars in the ordinate axis are different in the graphs corresponding to the immobilization groups from those in the recovery cohorts. Definition of abbreviations: HDAC3, histone deacetylase 3; OD, optical densities; a.u., arbitrary units; I, immobilization; R, recovery. Statistical significance is represented as follows: n.s., non-significant differences between any of the immobilized animals and non-immobilized controls; n.s., non-significant differences between any of the recovery groups of animals and the 7-day I mice. (D) Mean values and standard deviation of HDAC6 protein content in the gastrocnemius of the immobilization (top panel) and recovery (bottom panel) cohorts of mice, as measured by optical densities in arbitrary units (OD, a.u.). Note that as arbitrary units were used for the measurement of the optical densities in each set of immunoblots (see methods), scale bars in the ordinate axis are different in the graphs corresponding to the immobilization groups from those in the recovery cohorts. Definition of abbreviations: HDAC6, histone deacetylase 6; OD, optical densities; a.u., arbitrary units; I, immobilization; R, recovery. Statistical significance is represented as follows: n.s., non-significant differences between any of the immobilized animals and non- 
immobilized controls; n.s., non-significant differences between any of the recovery groups of animals and the 7-day I mice. (E) Mean values and standard deviation of SIRT1 protein content in the gastrocnemius of the immobilization (top panel) and recovery (bottom panel) cohorts of mice, as measured by optical densities in arbitrary units (OD, a.u.). Note that as arbitrary units were used for the measurement of the optical densities in each set of immunoblots (see methods), scale bars in the ordinate axis are different in the graphs corresponding to the immobilization groups from those in the recovery cohorts. Definition of abbreviations: SIRT1, silent mating type information regulation 2 homolog; OD, optical densities; a.u., arbitrary units; I, immobilization; R, recovery. Statistical significance is represented as follows: **, $\mathrm{p} \leq 0.01, * * *, \mathrm{p} \leq 0.001$, and n.s., non-significant differences between any of the immobilized animals and non-immobilized controls; $\S, \mathrm{p} \leq 0.05, \S \S$, $\mathrm{p} \leq 0.01$, and n.s., non-significant differences between any of the recovery groups of animals and the 7-day I mice.

Figure 5: (A) Mean values and standard deviation of acetylated FoxO1 protein content in the gastrocnemius of the immobilization (top panel) and recovery (bottom panel) cohorts of mice, as measured by optical densities in arbitrary units (OD, a.u.). Note that as arbitrary units were used for the measurement of the optical densities in each set of immunoblots (see methods), scale bars in the ordinate axis are different in the graphs corresponding to the immobilization groups from those in the recovery cohorts. Definition of abbreviations: FoxO1, forkhead box protein O1; AcFoxO1, acetylated FoxO1; OD, optical densities; a.u., arbitrary units; I, immobilization; $\mathrm{R}$, recovery. Statistical significance is represented as follows: *, $\mathrm{p} \leq 0.05, * * *$, $\mathrm{p} \leq 0.001$, and n.s., non-significant differences between any of the immobilized animals and non-immobilized controls; $\S, \mathrm{p} \leq 0.05, \S \S, \mathrm{p} \leq 0.01$, and n.s., non-significant differences between any of the recovery groups of animals and the 7-day I mice. (B) Mean values and standard deviation of acetylated FoxO3 protein content in the gastrocnemius of the 
immobilization (top panel) and recovery (bottom panel) cohorts of mice, as measured by optical densities in arbitrary units (OD, a.u.). Note that as arbitrary units were used for the measurement of the optical densities in each set of immunoblots (see methods), scale bars in the ordinate axis are different in the graphs corresponding to the immobilization groups from those in the recovery cohorts. Definition of abbreviations: FoxO3, forkhead box protein O3; AcFoxO3, acetylated FoxO3; OD, optical densities; a.u., arbitrary units; I, immobilization; R, recovery. Statistical significance is represented as follows: $*, p \leq 0.05$, and n.s., non-significant differences between any of the immobilized animals and non-immobilized controls; $\S$, $\mathrm{p} \leq 0.05, \S \S, \mathrm{p} \leq 0.01$, and n.s., non-significant differences between any of the recovery groups of animals and the 7-day I mice.

Figure 6: (A) Mean values and standard deviation of delta of the variables type I and type II fibers proportions of the immobilization (top panel) and recovery (bottom panel) cohorts of mice. Definition of abbreviations: I, immobilization; R, recovery. Statistical significance is represented as follows: $* *, p \leq 0.01$, and n.s., non-significant differences between any of the immobilized animals and the non-immobilized controls; n.s., non-significant differences between any of the $\mathrm{R}$ groups of animals and the 7-day I mice. (B) Mean values and standard deviation of delta of the variables fiber type I and type II cross sectional areas of the immobilization (top panel) and recovery (bottom panel) cohorts of mice. Definition of abbreviations: $\mu \mathrm{m}^{2}$, square micrometers; I, immobilization; $\mathrm{R}$, recovery. Statistical significance is represented as follows: *, $\mathrm{p} \leq 0.05$, **, $\mathrm{p} \leq 0.01$, and n.s., non-significant differences between any of the immobilized animals and the non-immobilized controls; $\S$, $\mathrm{p} \leq 0.05, \S \S, \mathrm{p} \leq 0.01$, and n.s., non-significant differences between any of the $\mathrm{R}$ groups of animals and the 7-day I mice. 
1

2

3

4

5

6

7

8

9

10

11

12

13

14

15

16

17

18

19

20

21

22

23

24

25

26

27

28

29

30

31

32

33

34

35

36

37

38

39

40

41

42

43

44

45

46

47

48

49

50

51

52

53

54

55

56

57

58

59

60

Table 1. MicroRNA assays and probes used for the quantitative analyses of the target genes using real-time PCR.

\begin{tabular}{|c|c|c|}
\hline Assay Name & Assay ID & miRBase accession number \\
\hline \multicolumn{3}{|l|}{ Muscle-specific, myomiRs } \\
\hline hsa-miR-1 & 002222 & MIMAT0000416 \\
\hline hsa-miR-133a & 002246 & MIMAT0000427 \\
\hline hsa-miR-206 & 000510 & MIMAT0000462 \\
\hline \multicolumn{3}{|l|}{$\begin{array}{c}\text { Other miRNAs } \\
\text { (highly expressed in muscles) }\end{array}$} \\
\hline \multirow[t]{2}{*}{$h s a$-miR-486 } & 001278 & MIMAT0002177 \\
\hline & & NCBI Accession number \\
\hline U6 snRNA, housekeeping gene & 001973 & NR_004394 \\
\hline
\end{tabular}

Abbreviations: ID, identification; hsa, homo sapiens; miR, microRNA; MIMAT, mature microRNA; snRNA, small nuclear RNA; NR, non-coding RNA RefSeq database category. 
A. Chacon-Cabrera et al. Fig. 1

A

Gastronemius muscle weights
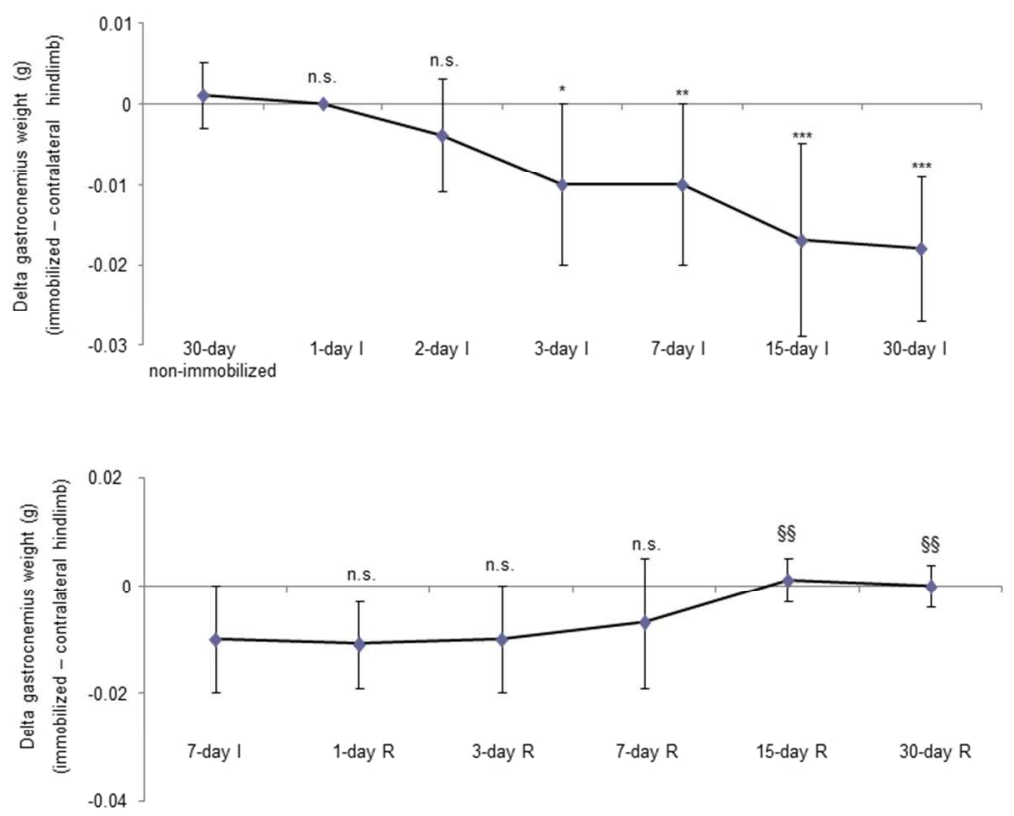

Figure 1A

$81 \times 60 \mathrm{~mm}(300 \times 300$ DPI $)$

John Wiley \& Sons, Inc. 
A. Chacon-Cabrera et al. Fig. 1
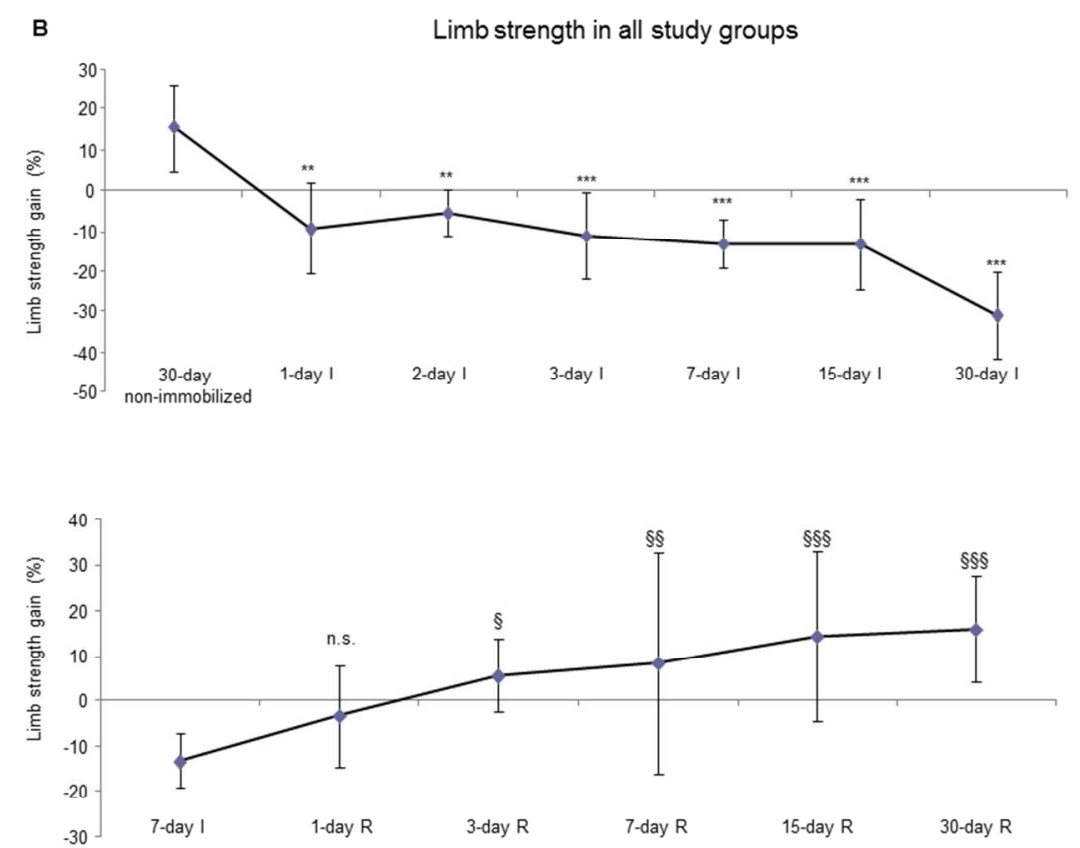

Figure 1B

$81 \times 60 \mathrm{~mm}(300 \times 300$ DPI $)$

35

36

37

38

39

40

41

42

43

44

45

46

47

48

49

50

51

52

53

54

55

56

57

58

59

60

John Wiley \& Sons, Inc. 
A. Chacon-Cabrera et al. Fig. 2

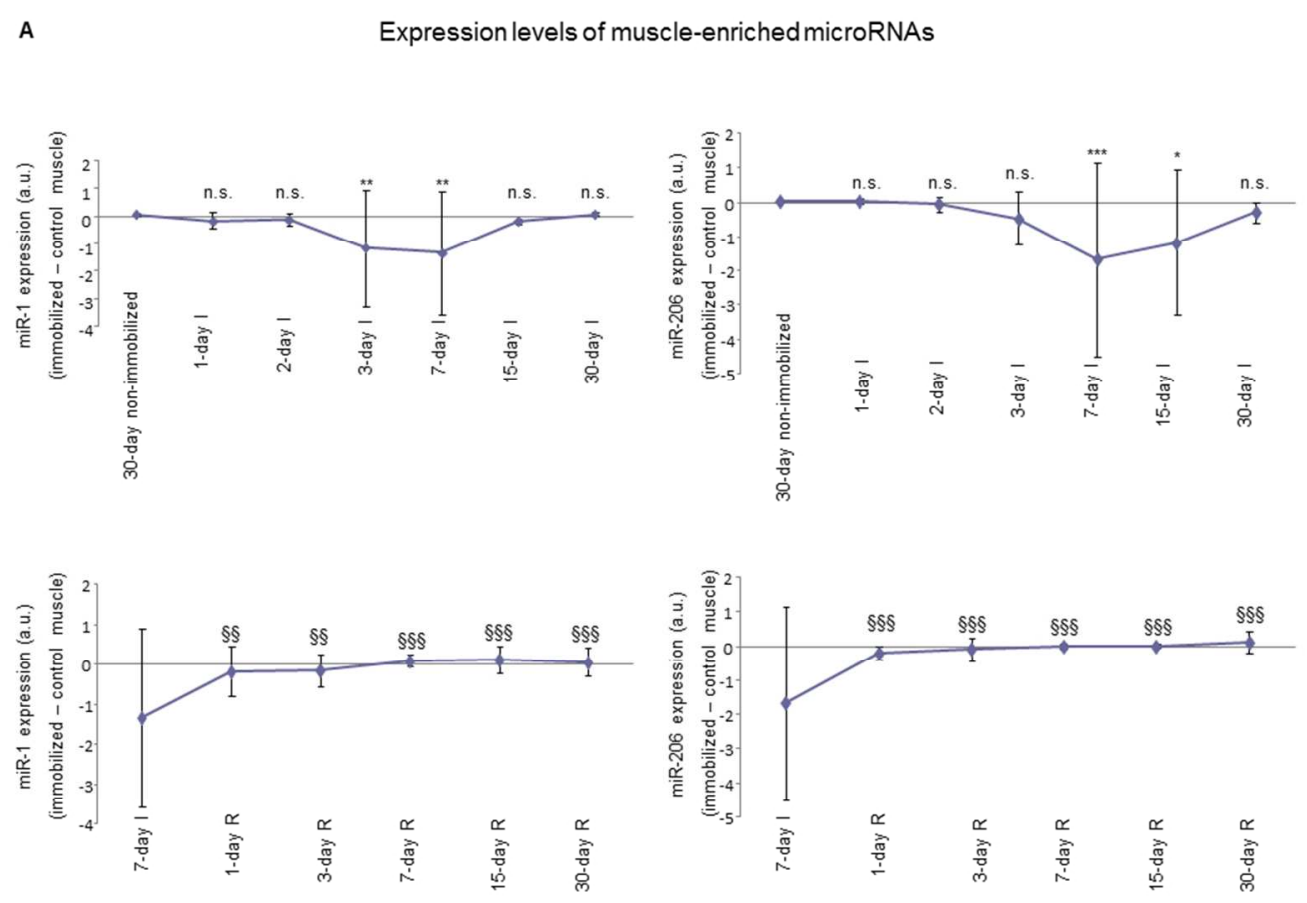

Figure 2A

$81 \times 60 \mathrm{~mm}(300 \times 300$ DPI $)$

John Wiley \& Sons, Inc. 
A. Chacon-Cabrera et al. Fig. 2

B

Expression levels of muscle-enriched microRNAs

(10

10

11

12

13

14

15

16

17

18

19

20

21

Figure 2B

$81 \times 60 \mathrm{~mm}(300 \times 300$ DPI $)$

John Wiley \& Sons, Inc. 


\section{A. Chacon-Cabrera et al. Fig. 3} Pax7 protein levels
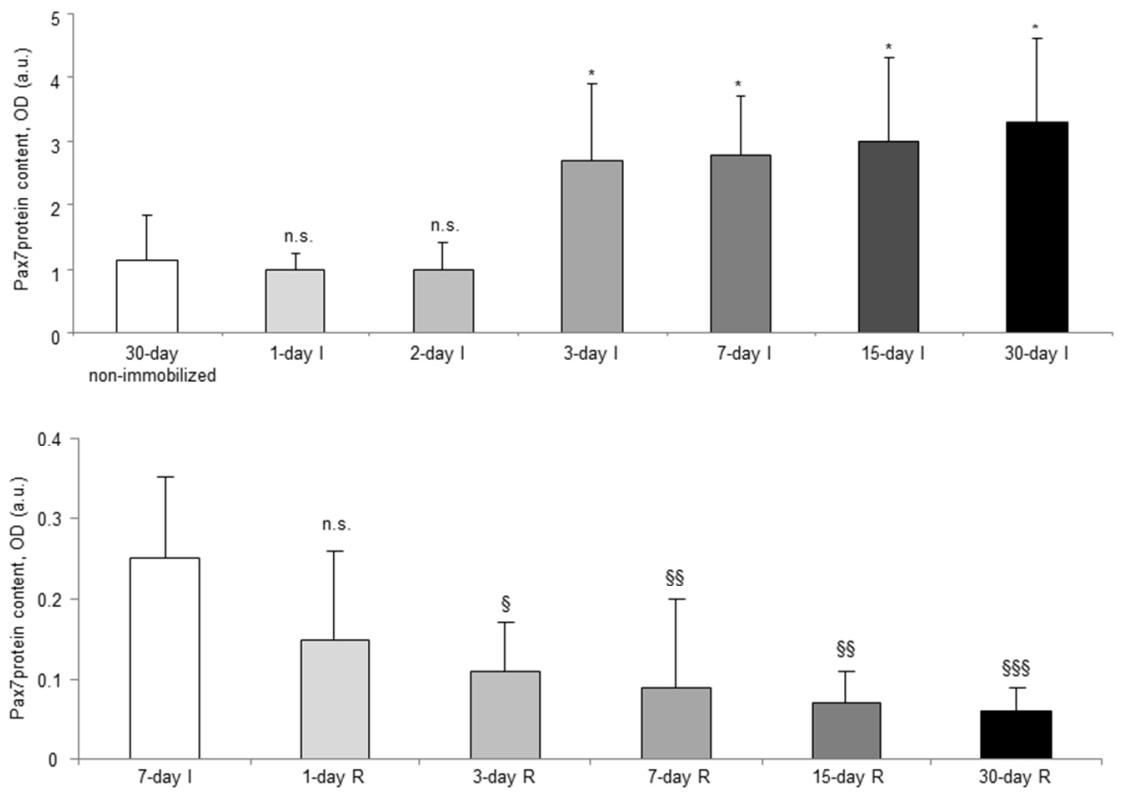

Figure 3

$81 \times 60 \mathrm{~mm}(300 \times 300$ DPI $)$

John Wiley \& Sons, Inc. 
A. Chacon-Cabrera et al. Fig. 4

A

Total protein acetylation
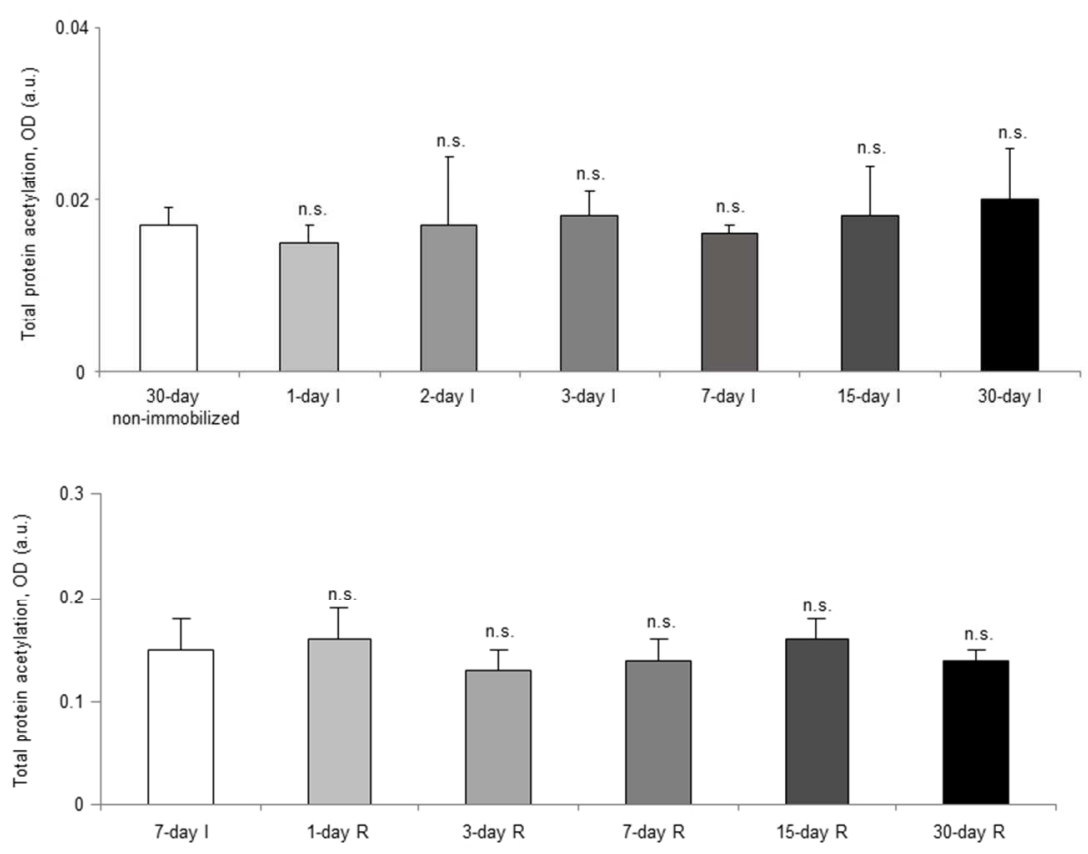

Figure 4A

$81 \times 60 \mathrm{~mm}(300 \times 300$ DPI $)$

35

36

37

38

39

40

41

42

43

44

45

46

47

48

49

50

51

52

53

54

55

56

57

58

59

60

John Wiley \& Sons, Inc. 
A. Chacon-Cabrera et al. Fig. 4

B

Acetylated histone 3
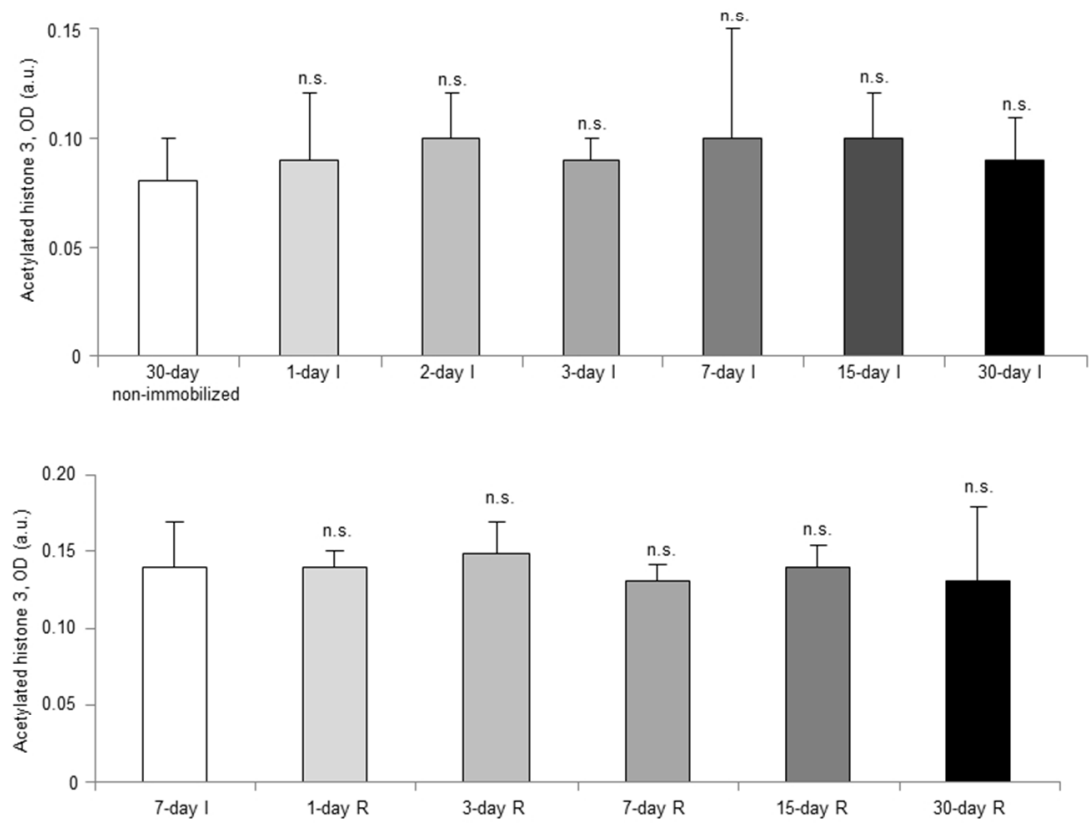

Figure 4B

$81 \times 60 \mathrm{~mm}(300 \times 300$ DPI $)$

John Wiley \& Sons, Inc. 
A. Chacon-Cabrera et al. Fig. 4

C

HDAC3 protein levels
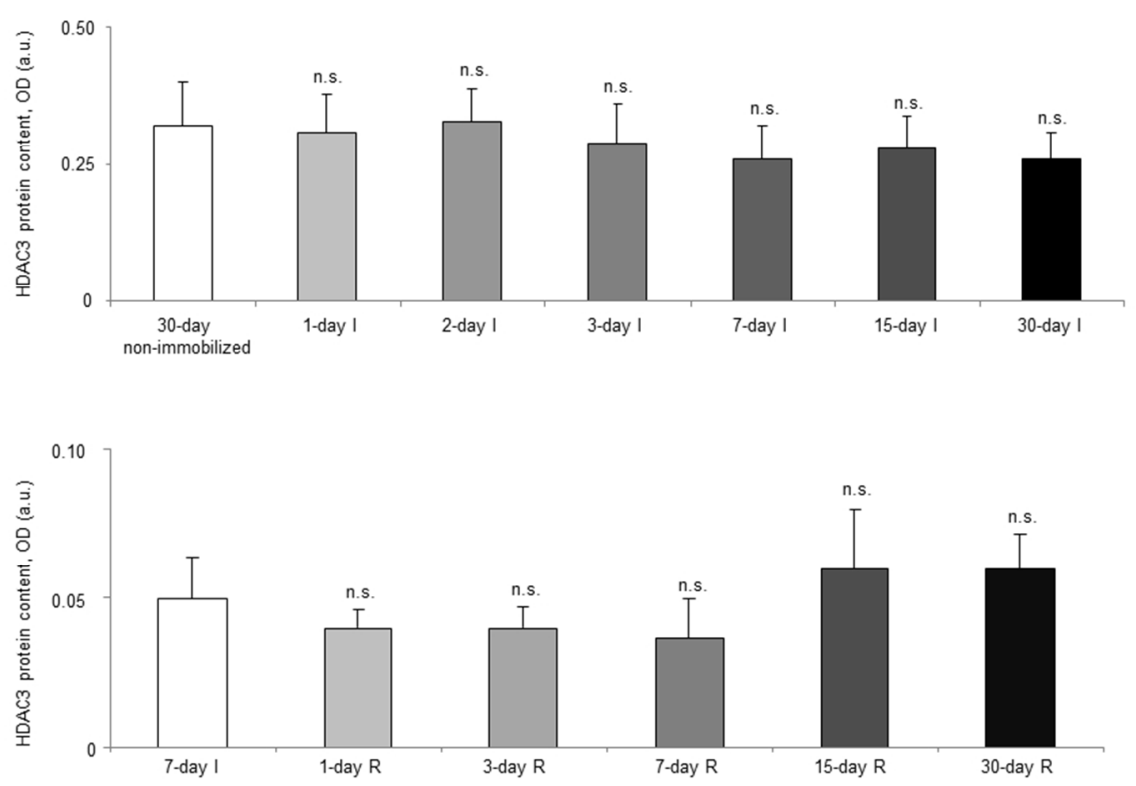

Figure 4C

$81 \times 60 \mathrm{~mm}(300 \times 300$ DPI $)$

35

36

37

38

39

40

41

42

43

44

45

46

47

48

49

50

51

52

53

54

55

56

57

58

59

60

John Wiley \& Sons, Inc. 


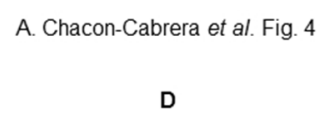

HDAC6 protein levels
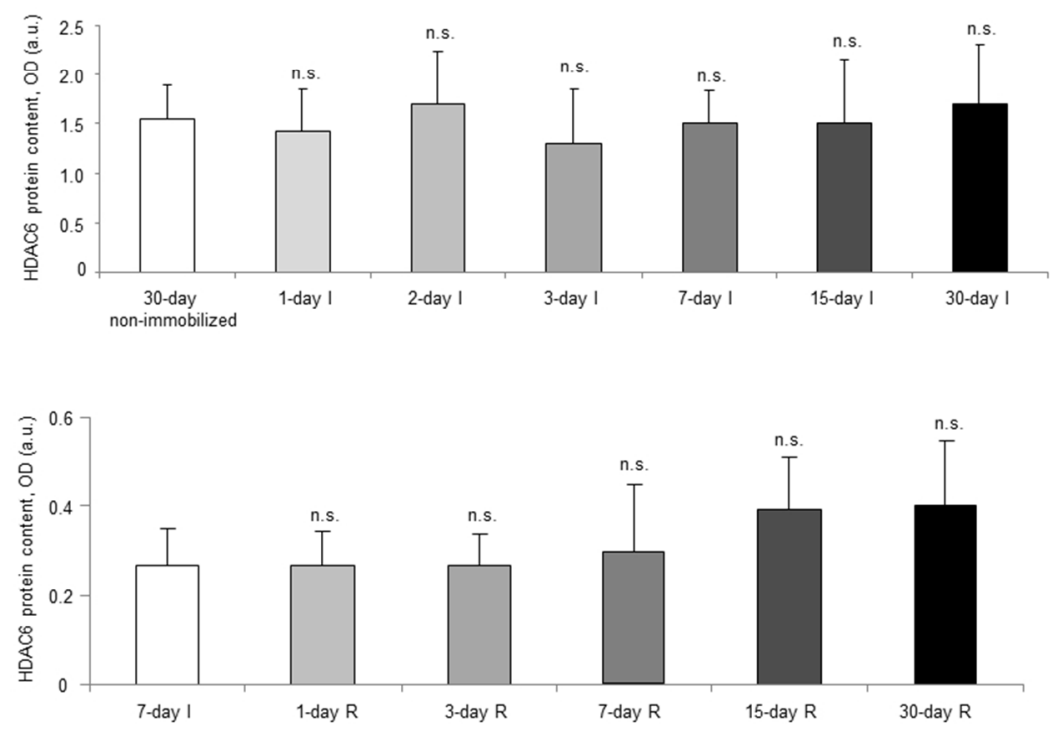

Figure 4D

$81 \times 60 \mathrm{~mm}(300 \times 300$ DPI $)$

John Wiley \& Sons, Inc. 
A. Chacon-Cabrera et al. Fig. 4

E

SIRT1 protein levels
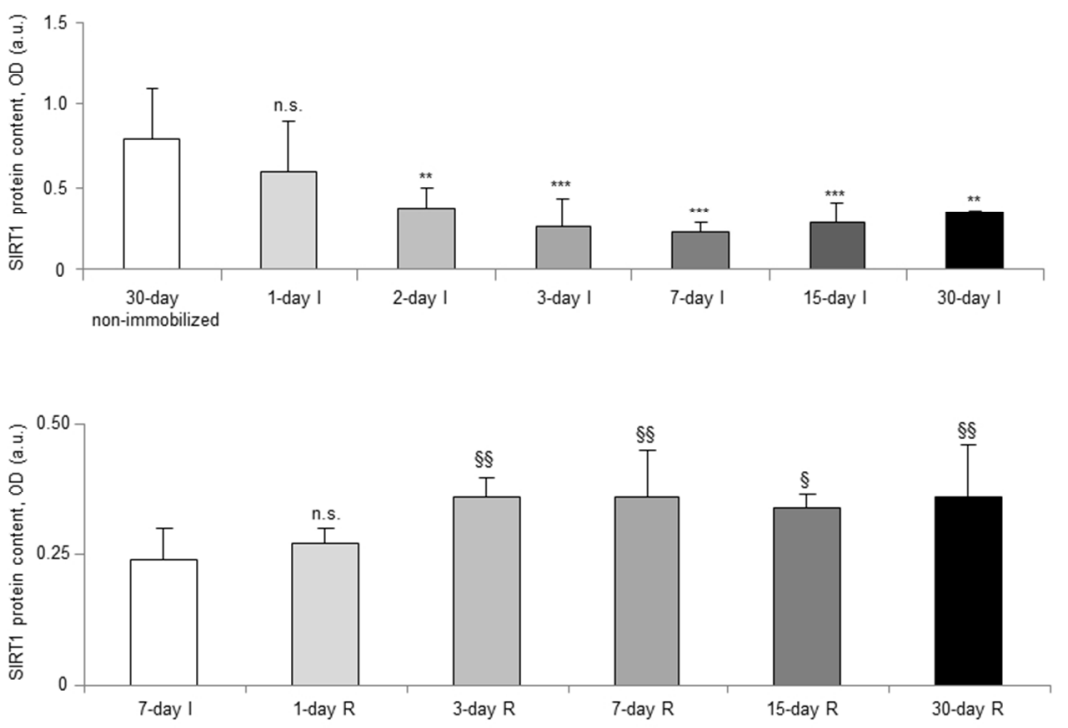

Figure 4E

$81 \times 60 \mathrm{~mm}(300 \times 300$ DPI $)$

John Wiley \& Sons, Inc. 

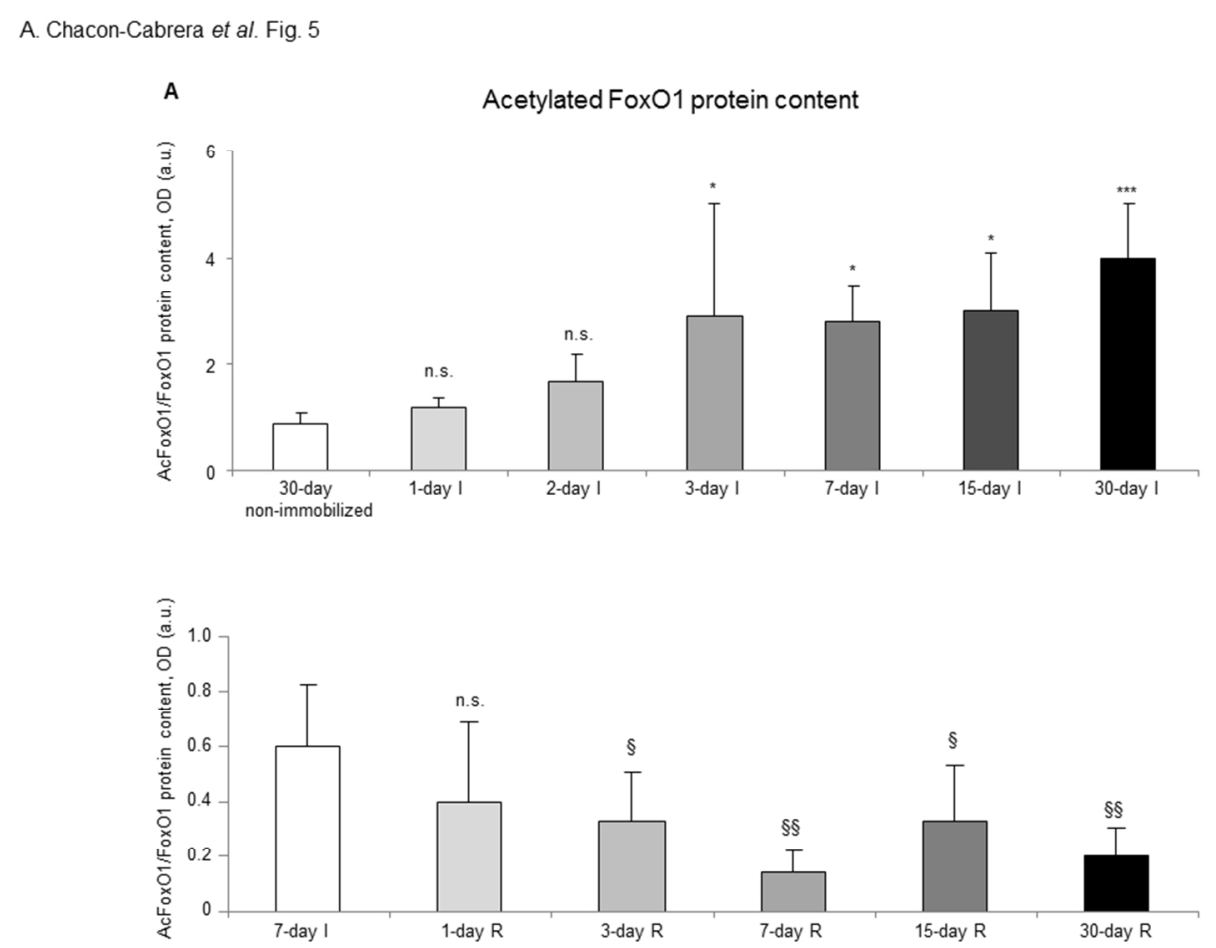

Figure 5A

$81 \times 60 \mathrm{~mm}(300 \times 300$ DPI $)$

John Wiley \& Sons, Inc. 
A. Chacon-Cabrera et al. Fig. 5

\section{B}

Acetylated $\mathrm{FoxO} 3$ protein content
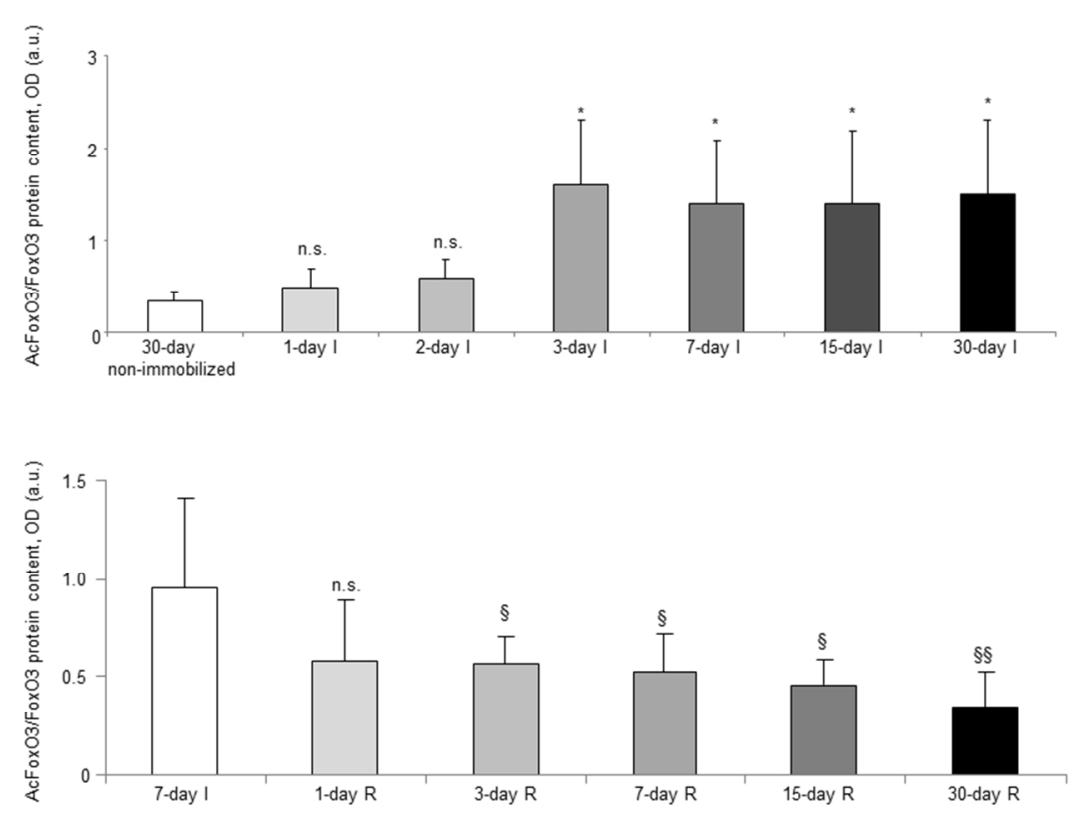

Figure 5B

$81 \times 60 \mathrm{~mm}(300 \times 300$ DPI $)$

35

36

37

38

39

40

41

42

43

44

45

46

47

48

49

50

51

52

53

54

55

56

57

58

59

60

John Wiley \& Sons, Inc. 


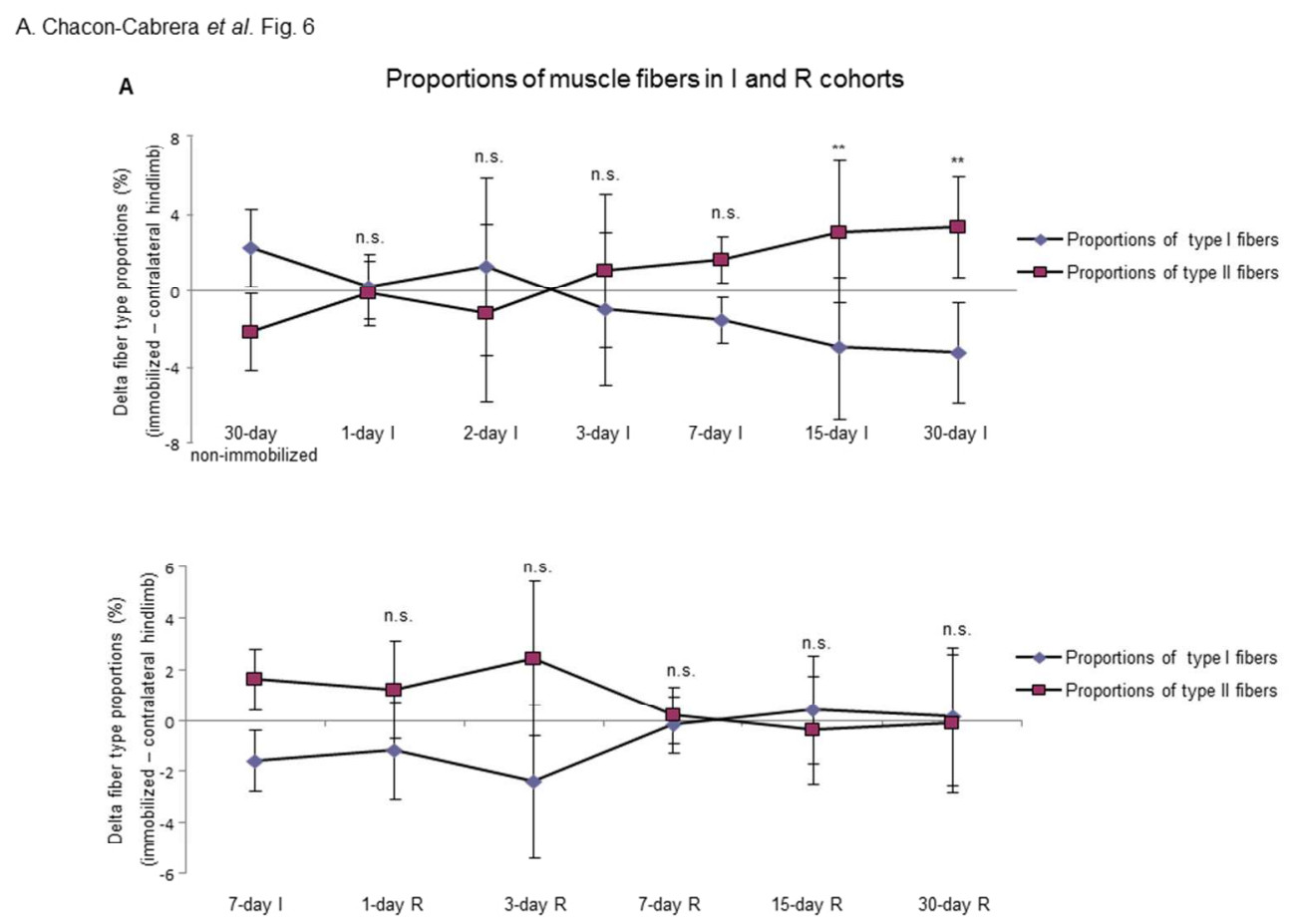

Figure 6A

$81 \times 60 \mathrm{~mm}(300 \times 300 \mathrm{DPI})$

John Wiley \& Sons, Inc. 
A. Chacon-Cabrera et al. Fig. 6
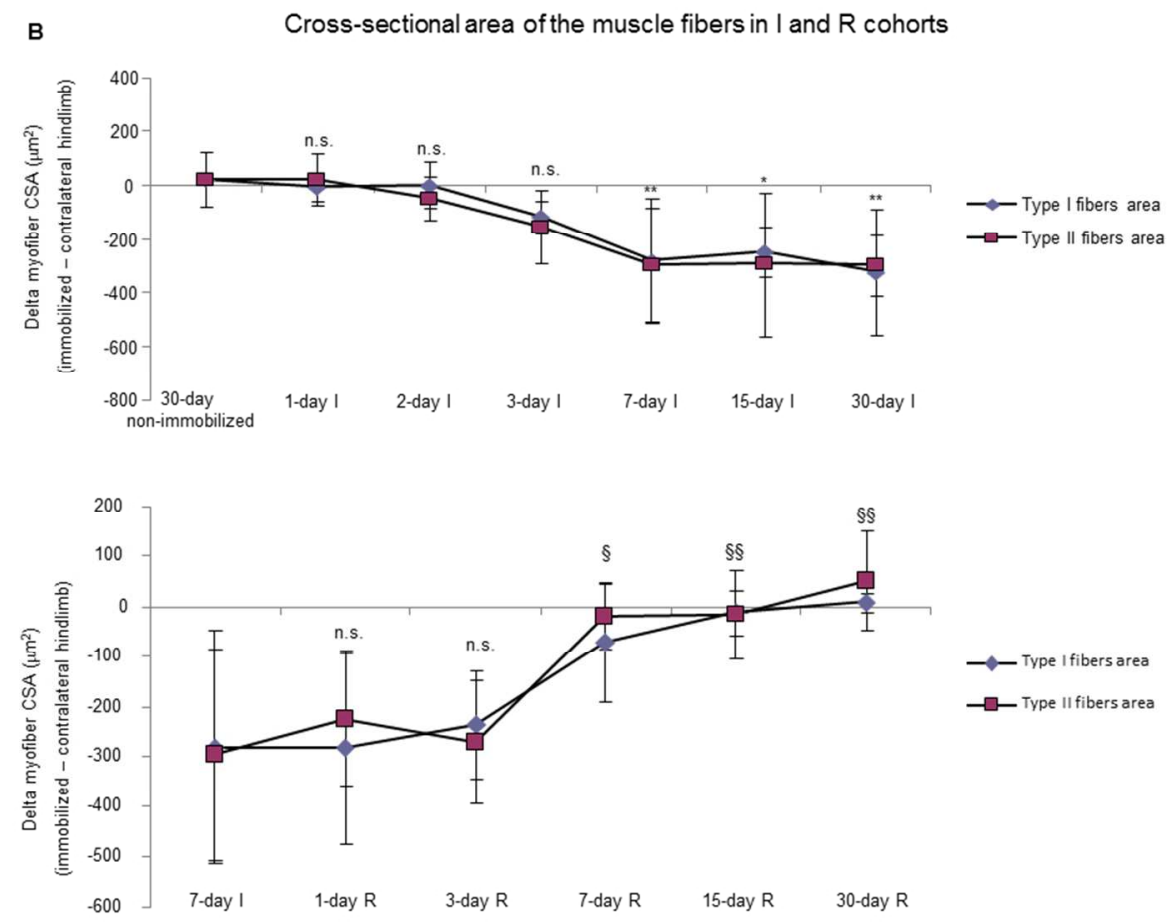

Figure 6B

$81 \times 60 \mathrm{~mm}(300 \times 300 \mathrm{DPI})$

John Wiley \& Sons, Inc. 